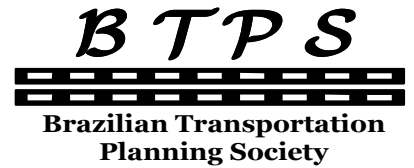

Planning Society
Journal of Transport Literature

Vol. 8, n. 1, pp. 52-94, Jan. 2014

Research Directory
JTL | RELIT

www.transport-literature.org ISSN 2238-1031

\title{
Peak-load pricing in public transport: a case study of Stockholm
}

[Precificação de carga de pico nos transportes públicos: um estudo de caso de Estocolmo]

\author{
Vilhelm Horn af Rantzien, Anna Rude* \\ Stockholm School of Economics - Sweden
}

Submitted 29 Dec 2012; received in revised form 17 Jan 2013; accepted 29 Jan 2013

\begin{abstract}
This paper studies how the price affects the demand for public transport in the peak- and off-peak period in the public transport in Stockholm. Further, the study investigates how differences in price elasticities of demand in the peak- and off-peak period can enable an increase in revenues as well as the total number of passengers while dampening the peak-load problem through price discrimination. The data is set up to examine the effect of the price on the number of passengers travelling by subway from January 1999 to December 2008. A number of control variables are used to isolate the effect of a price change in our econometric model. Thereafter, the elasticities of demand for each period are calculated in order to find Ramsey prices that can be used when a monopoly firm maximizes profit and minimizes the welfare loss. The study concludes that the price elasticities of demand differ between the peak- and the off-peak period and that SL should charge a higher price in the peakperiod and a lower price in the off-peak period to both increase their revenue, the total number of passengers, and reduce their problems associated with the peak-load demand.
\end{abstract}

Key words: peak-load, price elasticity, price discrimination, Ramsey pricing.

\section{Resumo}

Este trabalho estuda como o preço afeta a demanda por transporte público nos períodos de pico e fora de pico no transporte público em Estocolmo. Além disso, o estudo investiga como, por meio de discriminação de preço, as diferenças de elasticidadespreço da demanda nos períodos de pico e fora de pico podem permitir um aumento nas receitas, bem como o número total de passageiros, enquanto o problema do pico de carga é suavizado. Os dados são configurados para examinar o efeito do preço sobre o número de passageiros que viajam de metrô entre janeiro de 1999 e dezembro de 2008. Um conjunto de variáveis de controle é usado para isolar o efeito de uma mudança de preço no modelo econométrico utilizado. Depois disso, as elasticidades da demanda para cada período são calculadas a fim de encontrar os preços de Ramsey, que podem ser usados quando uma empresa monopolista maximiza lucros e minimiza a perda de bem-estar. 0 estudo conclui que as elasticidades-preço da demanda diferem entre o pico e o período fora de pico e que a empresa monopolista SL deveria cobrar um preço mais elevado no período de pico e um preço mais baixo no período fora de pico, tanto para aumentar a sua receita, o número total de passageiros, como para reduzir os seus problemas associados com a demanda de pico de carga.

Palavras-Chave: carga de pico, elasticidade-preço da demanda, discriminação de preços, precificação de Ramsey.

*Email: 20862@student.hhs.se.

\section{Recommended Citation}

Horn af Rantzien, V. and Rude, A. (2014) Peak-load pricing in public transport: a case study of Stockholm. Journal of Transport Literature, vol. 8, n. 1, pp. 52-94.

- JTL/RELIT is a fully electronic, peer-reviewed, open access, international journal focused on emerging transport markets and published by BPTS - Brazilian Transport Planning Society. Website www.transport-literature.org. ISSN 2238-1031. 


\section{Introduction}

The demand for public transport varies greatly over the course of a day. Most commuters travel during rush hours in the morning and the evening, while there is significantly less passengers during day and night time. These variations in demand over the 24 hours of the day leads to peak-load problems; the service provider has to invest in enough capacity to satisfy the peak-load demand, but these investments are not utilized when the demand drops. In addition, there is a cost of congestion if the capacity of the service provider is below the level that accommodates peak demand (such as longer travel times), as well as environmental costs caused by the congestion. (Boiteux, 1960)

Most operations that face peak-load problems differentiate prices charged for peak-period and for off-peak services in order to reduce variety in demand. For instance, hotels offer discounts on stays during off-season periods, and airline tickets are discounted when the demand is low. However, this attempt is seldom made in urban transportation, causing significant welfare losses, as pointed out by Vickrey (1963) ${ }^{1}$ already half a century ago:

"[...] in no other major area are pricing practices so irrational, so out of date, and so conducive to waste as in urban transportation. Two aspects are particularly deficient: the absence of adequate peak-off differentials and the gross underpricing of some modes relative to others" (Vickrey, 1963).

The public transport system in Stockholm, which is operated by Storstockholms Lokaltrafik (SL), is no exception to this rule. To date, no attempt has been made by SL to differentiate the prices charged for peak and off-peak services on a wide scale. In 2008 however, SL introduced an electronically charged ticket, the "Access-card". The card is based on new technology and has opened up new possibilities to employ peak-load pricing, by solving some of the practical difficulties (Damström, 2009).

The question of peak-load pricing with regards to SL has been discussed in earlier studies. A general weakness in these studies is the fact that they have not studied the price elasticities of

\footnotetext{
${ }^{1}$ Winner of The Sveriges Riksbank Prize in Economic Sciences in Memory of Alfred Nobel in 1996.
} 
demand in the peak- and off-peak periods separately. Instead, assumptions have been made regarding which type of tickets that are used in the peak- and off-peak period and thereafter, the peak- and off-peak periods' price elasticities of demand have been calculated using the elasticities of the different types of tickets. But there are reasons to believe these are not particularly plausible assumptions. If so, it would mean that the estimated gains from a peakload scheme could be severely off the mark. The aim of this study is to shed some light on whether the price elasticities differ across peak and off-peak periods by studying the peakand off-peak periods separately, and therefore avoiding the assumptions of which ticket-types that are used in the periods.

If a difference in elasticities between the peak- and off-peak period is found, a further aim is to demonstrate how SL could differentiate its prices in order to increase revenues and minimize the peak-load problem. The study is limited to the subway, where the peak-load problem is substantial due to the practical and economic difficulties of increasing peak-load capacity (Damström, 2009), and the effects of differences in earlier pricing policies have been relatively small.

The study is set up to analyze the effect of a change in price on the number of passengers during the peak- and the off-peak period. To isolate the effect of a price change on the number of passengers, a number of control variables have been used. The study is covering a ten year period, 1999-2008 and includes monthly data on the number of passengers traveling by subway in Stockholm.

The study is structured as follows: Section 1 presents the background of the study including salient features of SL, the theoretical background and results from previous research, and thereafter the hypothesis is presented in Section 2. Section 3 presents the empirical model, where necessary data delimitations as well as the dataset are explained. Also, in Section 3, the dependent and explanatory variables are presented and described, along with how the dataset is handled. In Section 4, the results from the multiple regression analysis along with the discussion of how the model is tested to show its validity are presented. Calculations of elasticities and Ramsey prices are also presented in Section 4. Finally, in the concluding section, the results from the regression are analyzed and discussed along with some proposals for future research. 


\section{Background}

\subsection{Some salient features of $S L$}

Storstockholms Lokaltrafik, SL, is owned by Stockholm County, and its board consists of politicians elected by the County Council. Almost half of the activities are financed via ticket revenues, advertising and rent for premises. The other half is tax financed in the form of contributions from the County Council (Stockholm Public Transport, 2009).

The public transport is today considered as a part of the social services provided by the government. The Swedish government has the aim to "provide a satisfactory transportation service"2 (Prop. 1997/98:56) to all citizens which calls for a public transport service that is well-developed and has a wide coverage.

The political importance of affordable urban transportation in Stockholm is obvious, given the level of tax funding SL has received. However, due to differences in political views, SL has been granted different levels of tax funding depending on the political party in power. The general tendency in the last years has been towards a lower tax funding level, see Figure 1.

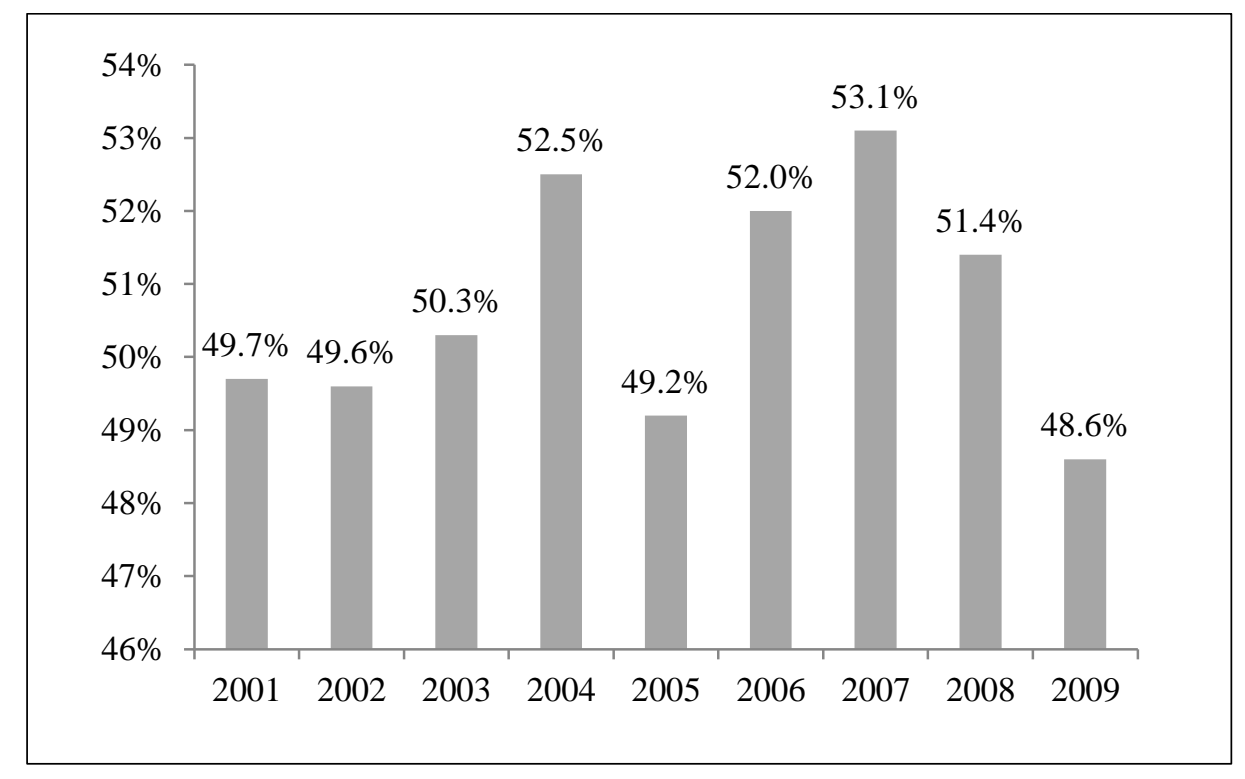

Figure 1 - Tax funding level (in percent) evolution ${ }^{3}$

\footnotetext{
${ }^{2}$ Translation made by the authors.

${ }^{3}$ Source: SL Annual Report (2009).
} 


\subsubsection{Criteria for a new pricing policy}

The WSP Report (2009) summarizes the criteria that SL has to consider when choosing a pricing policy. The main criteria are that pricing has to be socially efficient, fair and comprehensible. In addition, SL should strive to reduce its dependence on tax funding as well as to increase the number of passengers.

The Swedish Parliament states that "the general goal for the transportation policy is to ensure socially efficient and sustainable transportation to the citizens and the economy" ${ }^{4}$ (Prop. 1997/98:56). One step towards meeting the criterion of economic efficiency is to charge the passengers fares that reflect the social marginal costs evoked by their travel. This will incentivize passengers to choose the socially efficient alternative.

To ensure that a pricing policy is politically feasible and persistent, it is of importance that it is perceived as fair. The notion of equity is a central part of SL's criteria and goals. However, this criterion is hard to define. Injustices that are accepted today often provoke less criticism than a new injustice, even if it objectively is fairer than the old injustice.

SL also emphasizes the need for a pricing policy that is comprehensive. This refers to a pricing policy that is both easy to administer and easily understood by the passengers. The electronically charged Access-card makes the administration of charging different prices to peak- and off-peak passengers easier (Damström, 2009).

\subsection{Theoretical background}

Urban public transport fares face a number of needs and requirements, and some of them are contradictory. On the one hand, there is pressure to charge high prices to fulfill budgetary requirements, or provide dividends to owners. Politicians' wishes to reduce public expenditure (reduce subsidies) can put further upward pressure on the prices. On the other hand, there are also pressures to keep the prices low. These pressures come from objectives such as inclusion, equity and corrections for under-priced private transport. (Fearnley, 2004)

\footnotetext{
${ }^{4}$ Translation made by the authors.
} 
SL has experienced a cut in subsidies, and this tendency is mirrored in many other European countries (Higginson, 2002). Efficiency gains in the urban transportation industry can explain parts of these cuts. However, they also represent transfers of cost, from the public sector to the passengers, in the form of higher prices and/or reduced service levels. (Fearnley, 2004)

The cut in subsidies increases the need for SL to cover costs through ticket sales, and to adopt an efficient pricing scheme. As described by Fearnley (2004), general fare policies seldom address the concern of efficient cost recovery that is efficient. Therefore, some basic aspects of pricing for an operation such as that of SL are presented below.

\subsubsection{Marginal cost pricing}

A necessary condition for Pareto optimal resource allocation in the case of a standard type of good is that price equals marginal cost (MC). There is however a concern with marginal cost pricing with regards to urban transport, due to some special features of both supply and demand (Fearnley, 2004).

The MC may be substantially higher during peak-period than during the off-peak period. Studies have shown that both the short run marginal cost (SRMC) and the long run marginal cost (LRMC) tend to be higher the peak-period. (Boiteux 1960)

The SRMC increases in the production volume since there is limited room for increases in capacity in the short run, and the increase may be substantial. In addition, congestion may also increase the short run marginal social cost due and increase in travel times, the discomfort of crowding and environmental problems. (Boiteux 1960)

In the long run, SL may be able to invest in enough capacity to transport all the individuals wishing to travel in the peak-hours, but this capacity is used little or not at all during the offpeak periods, leading to a higher LRMC. Figure 2 illustrates how the extra capacity used to satisfy the peak-load demand is unutilized during the off-peak hours.

Regardless of whether the time horizon is short or long, peak-period passengers are associated with higher marginal costs, and should be charged higher prices than off-peak passengers. However, the firm can charge the Pareto efficient marginal prices through the practice of price discrimination, as described below. 


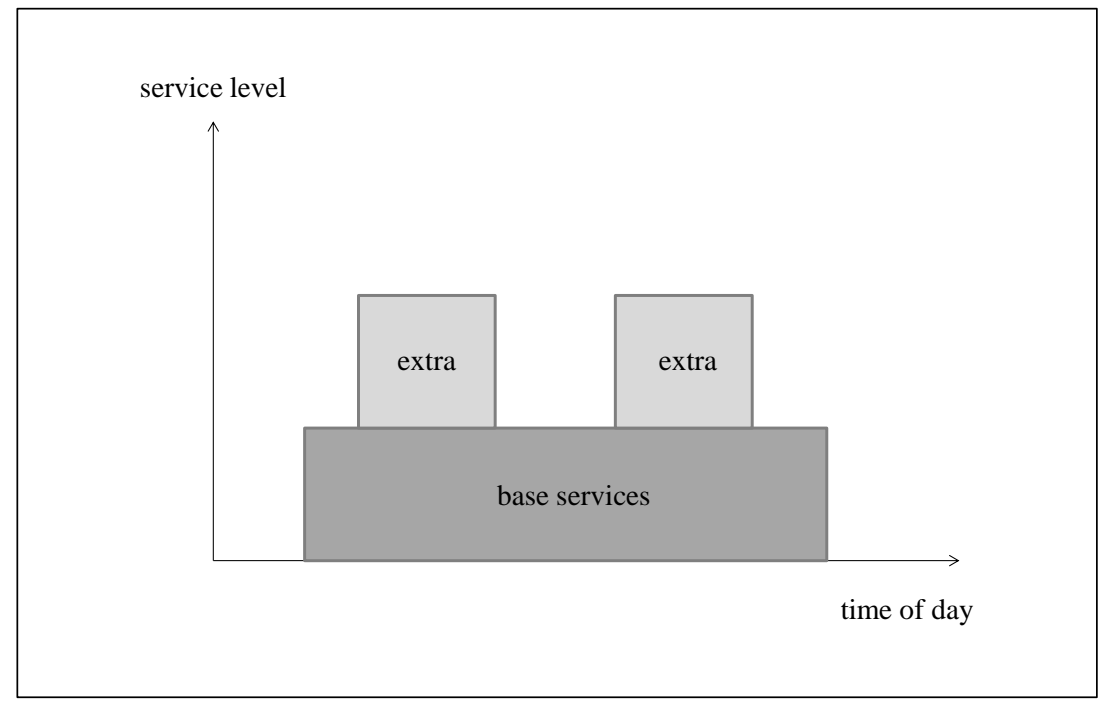

Figure 2 - Extra service level required to serve the peak-load.

\subsubsection{Price discrimination - Ramsey pricing}

In order to recover the differences in marginal costs between the peak- and off-peak period, and give the passengers incentive to change their travelling behaviour, SL can price discriminate. Price discrimination occurs when a firm charges different groups of customers different prices for an identical good or service. Price discrimination may be profitable when consumers differ in their willingness to pay. (Pigou, 1929)

An illustrative example is a firm that serves two passenger groups equal in size (peak-and offpeak period) that differ in how much they are willing to pay for the service. For example, peak-period passengers may be willing to pay 5 and off-peak period passengers 2 for the travel. If marginal costs are equal in both the peak- and off-peak period then the firm would charge 5 to maximize profits if prices were uniform. This would leave the off-peak passengers without the service. If, however, the firm could price discriminate they could yield higher profits and at the same time serve both passenger groups given that the marginal cost of providing the service was less than 2 . This indicates that firms that charge uniform prices tend to focus on the customers who are willing to pay the highest price.

For a firm to successfully price discriminate there are three conditions that have to be fulfilled (Perloff, 2007). 
- Market power - the firm has to have market power otherwise it cannot charge any customer more than the price of the competitors.

- Sensitivity - consumers must have different demand elasticities and the firm must be able to identify how the consumers differ in their sensitivity of demand.

- Prevent resales - the firm must be able to prevent resales. Price discrimination does not work if resales are possible because then only low-price sales would be possible.

In the case of SL it is clear that condition one and three are fulfilled. In this study it will be examined whether SL's customers differ in their elasticity of demand. If so, SL satisfies the three conditions and can price differentiate, according to the theory.

Pigou (1929) identifies three types of price discrimination. In first-degree price discrimination the prices varies with each customer's willingness or ability to pay, and each unit is sold at a separate price. This requires that the firm is able to identify each sold unit. There are rare instances of such pricing in practice. In second-degree price discrimination the situation is the opposite: the firm cannot distinguish consumers at all. However, the firm has knowledge concerning the distribution of consumer characteristics, and offers a menu of contracts that make consumers self-select. An example is mobile phone contracts. Lastly, in the case of third-degree discrimination the firm is able to identify groups of consumers, and to charge different prices for the different groups. Third-degree discrimination can be applied by SL so that peak-period passengers are charged a higher price than those travelling in the off-peak period. There are many examples of this, for instance prices that differ according the geographical market, or the age of consumers.

One type of price discrimination used to minimize the welfare loss caused by a budget constraint (by insufficient subsidies for example) is Ramsey pricing. According to the Ramsey pricing rule, prices are differentiated according to the market-segments' differences in the willingness to pay (price elasticities of demand). The pricing rule summarizes the relationship between price elasticities of demand and the optimal monopoly price. (Ramsey, 1927)

This pricing strategy is proposed by the World Bank (Kessides and Willing, 1998) as a method to get efficient pricing in public transport, since it takes into consideration the demand and the cost side, as well as the budget constraint. 
Baumol and Bradford (1970) present a traditional model for optimal pricing under budget constraint for a monopolist supplier of two goods.

The general pricing rule for third degree price discrimination is:

$$
\frac{\frac{\mathrm{P}_{1}-\mathrm{MC}_{1}}{\mathrm{P}_{1}}}{\frac{\mathrm{P}_{2}-\mathrm{MC}_{2}}{\mathrm{P}_{2}}}=\frac{\varepsilon_{2}}{\varepsilon_{1}}
$$

Where $P$ is price, $M C$ is marginal cost and $\varepsilon$ is the elasticity of demand.

This is the common way to represent Ramsey pricing. In the case where prices are higher than marginal cost, due to a budget constraint, efficient pricing of two services is a proportional change in the markup, above the marginal cost, equal to the inverse ratio of the elasticities of demand. As can be seen above, a scenario with the same elasticities in both markets leads to the same proportional mark-up over marginal cost in all markets, the result would be no price discrimination.

Although Ramsey pricing is welfare maximizing under certain circumstances, it is rarely applied in local public transport. There are several reasons for this. Firstly, it assumes detailed knowledge of cost and demand structures, which are usually difficult to obtain. Secondly, regulating authorities are not always happy with great variations in fares. Thirdly, the correct Ramsey price can in some instances be a very large mark-up over marginal cost (Nilsson 1992). Fourthly, Ramsey pricing is not efficient any longer when external costs and benefits are present. Baumol (1995) argued however that these latter effects are likely to be relatively small.

\subsubsection{Price elasticity of demand}

In order to calculate the optimal prices under the Ramsey pricing rule, the price elasticities of demand are needed. As explained by Perloff (2007), the price elasticity of demand measures the price sensitivity, which is defined as the percentage change in demand resulting from a one percent change in price, ceteris paribus. A high price elasticity of demand indicates that the demand for the service, or good, is sensitive to changes in price, namely that a small change in price has a large effect on the demand. A low price elasticity indicates that a price change has a small effect on demand. 
A common way to calculate price elasticities of demand is to assume a linear demand. The price elasticity of demand is defined as,

$$
\varepsilon=\frac{\text { percentage change in quantity demanded }}{\text { percentage change in price }}=\frac{\left(\frac{\Delta \mathrm{Q}}{\mathrm{Q}}\right)}{\left(\frac{\Delta \mathrm{P}}{\mathrm{P}}\right)}=\left(\frac{\Delta \mathrm{Q}}{\Delta \mathrm{P}}\right) *\left(\frac{\mathrm{P}}{\mathrm{Q}}\right)
$$

where $Q$ is the quantity and $P$ is the price.

Assuming a linear demand function,

$$
Q=a-b P
$$

where $a$ is the quantity demanded when price is zero, $b$ is the ratio of the fall in quantity due to an increase in price $(\mathrm{P})$, the price elasticity of demand can be expressed as:

$$
\varepsilon=\left(\frac{\Delta \mathrm{Q}}{\Delta \mathrm{P}}\right) *\left(\frac{\mathrm{P}}{\mathrm{Q}}\right)=-\mathrm{b}\left(\frac{\mathrm{P}}{\mathrm{Q}}\right)
$$

However, when a monopolist like SL is to interpret the possible effects of the price elasticities of demand, they have to be aware of the impact on the revenue. Equation 2 shows how marginal revenue of a monopolist depends on the price elasticity of demand.

$$
M R=P\left(1+\frac{1}{\varepsilon}\right)
$$

Furthermore, the following important relationships hold.

- If the value of the elasticity is in the range zero to -1 (inelastic), then fare increases will lead to increased revenue since the expression $1+\left(\frac{1}{\varepsilon}\right)$ is less than zero. As a result, if the price elasticity of demand is inelastic SL can increase total revenue by charging higher prices even though the number of passengers will decrease.

- If the elasticity exceeds -1 , then a fare increase will lead to a decrease in revenue since $1+\left(\frac{1}{\varepsilon}\right)$ then will be greater than zero. SL can then increase revenue by lowering their prices leading to increase in the number of passengers. 
Figure 3 illustrates the marginal revenue and price elasticity of demand for a linear demand curve. Over the range where demand is elastic the marginal revenue is positive and over the range where demand is inelastic the marginal revenue is negative. The revenue is zero when the demand is unitary elastic.

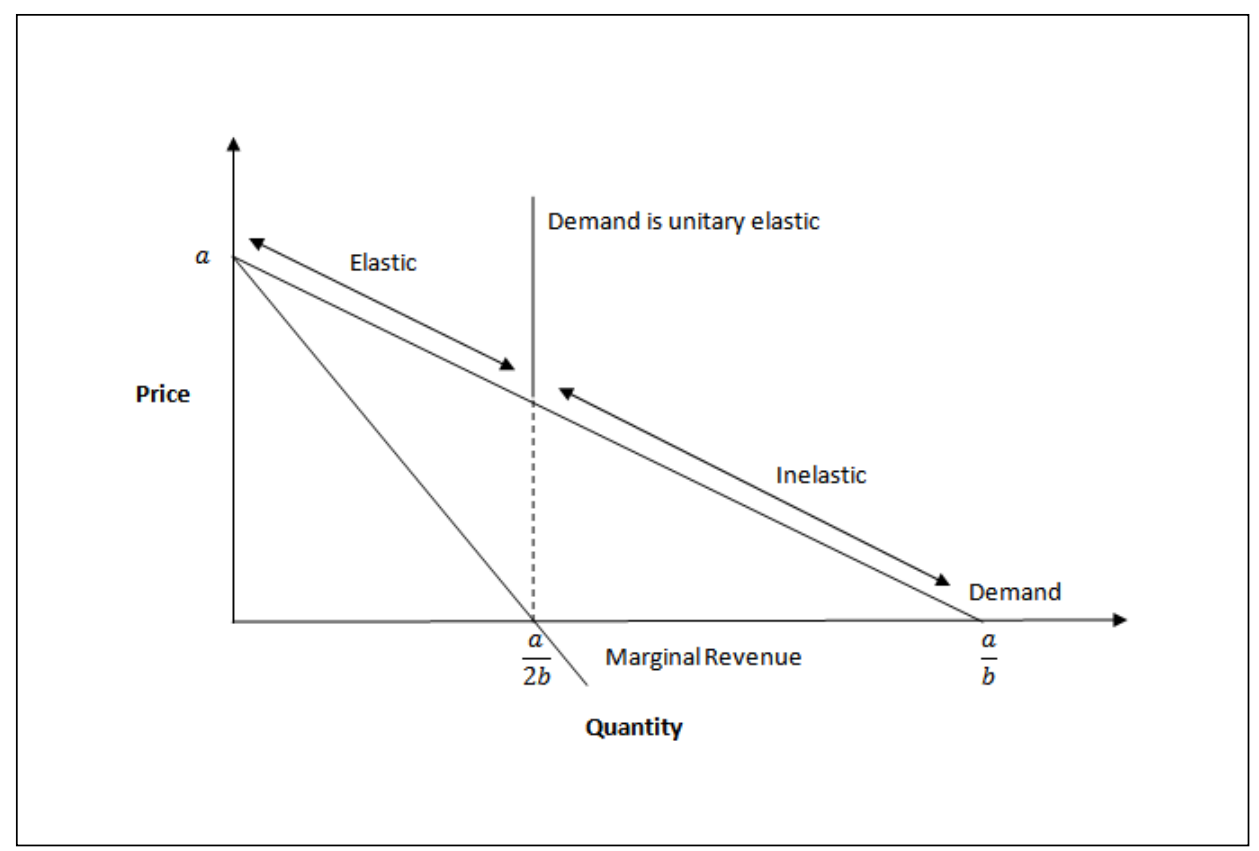

Figure 3 - marginal revenue and price elasticity of demand for a linear demand curve ${ }^{5}$

\subsection{Results from previous research}

There have been many international studies on price elasticities of demand in public transport. Unfortunately, very few studies have distinguished between the elasticities for the peak- and off-peak periods despite the fact that demand is expected to differ substantially in these two periods (Oum et al., 1992). All studies indicate however that the elasticity is generally inelastic, and higher in the long run, than in the short run, as would be expected.

The TRL study on the public transport in London (Balcombe et al., 2004) summarizes a number of typical findings on elasticities. It highlights that elasticities of demand for bus trips are higher than those of the subway. This reflects the advantages of using subway as a way to commute from outer urban area to the city centre for commuters. This finding follows the findings of Pratt et al. (2000). Pratt's study also classified its elasticities as peak- and off-peak

\footnotetext{
${ }^{5}$ Source: Besanko (2002).
} 
period elasticities, and finds that the UK off-peak elasticity values are about twice the peakperiod values.

Fearnley (2004) summarizes other typical findings:

- Leisure trips are more price sensitive than business trips. This is due to the fact that those passengers are more flexible in regards to the choice of whether to travel or not and if so, when and where.

- Car ownership increases the elasticity of demand since it offers an alternative to public transport.

- Youths and children have a higher elasticity of demand than adults.

- Low-income groups are less sensitive to price change than high-income. This reflects the lack of choice low income groups have with regards to transportation.

International findings with regards to subway elasticities are presented in Table 1. Very few of the studies are explicit about which time horizon their elasticities refer to. Consumers can change their assets (e.g. car ownership) and/or where they live in the long run whereas it is not possible in the short run. However, according to Oum et al. (1992) no estimation of a full long run model has been conducted because of the complexity of analyzing and modeling the transport decisions, asset ownership and location choice jointly.

Studies on the public transport in Stockholm conclude that the general price elasticity of demand for public transport is -0.52 and the corresponding elasticity for subway and rail services is -0.56 (Transek, 2005). The Transek (2005), and Olsson, Tegnér and Gustafsson (2000) studies have however not calculated the price elasticities of demand for the peak- and off-peak periods separately, but calculated the elasticities of demand on different ticket types and thereafter made assumptions on which kind of tickets that are used in each period to calculate the effect of peak-load pricing. 
Table 1 - Subway price elasticities of demand from previous studies ${ }^{6}$

\begin{tabular}{lr}
\hline Study & Elasticity \\
\hline Chicago Metro. price increases (Cumming et al.,1989) & -0.34 \\
BART San Francisco (Reinke, 1988) & -0.31 \\
Express underground - 2 (Doi and Allen, 1986) & -0.25 \\
Express underground - 3 (Doi and Allen, 1986) & -0.24 \\
Express underground - 1 (Doi and Allen, 1986) & -0.23 \\
Mean & -0.21 \\
New York metro North (Charles River Associates, 1997) & -0.20 \\
Chicago Metro (LTI Consultants Inc. and E. A. France and Associates 1988) & -0.18 \\
New York 1970-95 (Mayworm, Lago and McEnroe, 1980) & -0.16 \\
New York 1995 (Charles River Associates, 1997) & -0.15 \\
\hline
\end{tabular}

This study intends to make a small contribution toward remedying this undesirable state of affairs by analyzing separately the price sensitivity of demand for travelling on subway during both the peak-period and the off-peak periods.

\section{Hypothesis}

Previous research and theories indicate that the peak-load problem can be partially solved by implementing a suitable pricing policy. Previous studies indicate that the price elasticity of demand for passengers travelling in the off-peak period is higher than in the peak-period. Passengers in the peak-hours are described as having less flexibility due to factors such as work hours leading to a lower sensitivity to price changes.

In order to test our hypothesis below, two regressions will be made. The first regression is made to test if price affects travelling in the peak-period, and the second will test if price affects travelling in the off-peak period. If the price parameter is significant in both regressions, a further analysis of this variable is of pertinence.

\footnotetext{
${ }^{6}$ The elasticities are sorted in a descending order.
} 
- $\quad \boldsymbol{H}_{\mathbf{0}}$ : The variation in the number of passengers over time cannot be explained by the variation in price.

- $\boldsymbol{H}_{\mathbf{1}}$ : The variation in the number of passengers over time can be explained by the variation in price.

The null hypothesis will be rejected if the price-parameter is statistically significant.

\section{Empirical model}

\subsection{Data}

To analyze if a change in price has a different effect on demand in peak- and off-peak period, a number delimitations are necessary. This includes which time period, geographic area and what price parameter is to be used.

\subsubsection{Choice of time period}

The time period has been chosen in order to obtain as large a sample as possible of reliable data. Due to changes in measuring standards as well as the lack of availability of data, the year 1999 is chosen as a start-date in order to maximize the number of reliable observations. The ending date is in the end of 2008 since this is the latest date with available data.

\subsubsection{Choice of price parameter}

The study uses the changes in price of the 30-day travel card as a proxy for price changes in all types of tickets. A primary reason is to simplify the analysis as the percentage price increases of the different tickets are equal in size, and occur simultaneously with very few exceptions. Therefore, including more price parameters only dilutes the effects of the price increases and causes multicollinearity ${ }^{7}$. Further, the 30-day travel card stands for the largest ticket sales as well as fare revenue, making it the most interesting and relevant price

\footnotetext{
${ }^{7}$ A high degree of linear relationship between two or more explanatory variables in a regression can lead to large variances for the slope estimators which lessens the preciseness of the estimators (Woolridge, 2009).
} 
parameter to use. During the chosen time period the fare revenue from the 30-day travel card amounted to, on average, 60 percent of total ticket revenue ${ }^{8}$.

\subsubsection{Choice of geographic area}

From Jan 1999 to May 2006, SL has had a pricing policy based on a five-zone model. In May 2006, a flat rate pricing policy was introduced. In the flat rate model, a flat rate was used resulting in the same cost of travelling independent on where the journey started. Thereafter, in May 2007, the zone pricing model was reintroduced, this time based on three zones. In the zone pricing models, passengers pay in accordance with how many zones they travel through. Since the zones are split up in accordance to how far from the city centre they are, a trip from far outside Stockholm is more expensive than one within the city-centre.

The choice of geographic area is of significant importance for several reasons. First, the differences in pricing policies over the past decade will impact our results in a significant way if the geographical area is not chosen with care. In choosing the geographic area the aim has been to find an area where the difference in pricing policies has had a minimum effect on the cost of travelling. In this paper the subway is chosen as it has, during the last ten years, in general been in the most central zone and thus has been unaffected by the change from a fivezone pricing model to a flat rate model and then back to a three zone model.

The whole subway network has, with the exception of only a few stations, has been in the most central zone in all pricing models used by SL. In the five zone model, the central zone includes the zones 1 and 2, and in the three zone model the central zone is A, where the cost of travelling was the minimum price charged by SL regardless of which subway-station the passengers started their journey - see Appendix A. Thus, the choice of the subway as a geographical delimitation minimizes the external price effects caused by the change in pricing policies on our price.

This delimitation is not required when only analyzing the effect of a price change of the 30day card on the number of passengers, since this card enables travel at a fixed price regardless of how far from the city center the trip started. However, since we use this price parameter as

\footnotetext{
${ }^{8}$ Average calculated from Annual Report 1999-2008
} 
a proxy for all types of tickets this delimitation is of importance in order to be able to draw conclusions for all types of tickets.

Further, a consistent measuring standard has been used for the passengers in the subway over the past decade, making it a more reliable source of data when compared to the data available for other public transport. Finally, it is in the subway that the peak-load problem is most apparent for practical reasons; it is both costly, and often impossible, to put more trains in service.

\subsection{Data collection}

\subsubsection{The data set}

Tegnér (2002) has been a guideline in deciding upon what variables to include in the regression. The following data has been collected:

- Number of passengers travelling with SL's subway, 1999-2008, monthly figures (in thousands).

- Development on the price of the 30-day travel card, 1999-2008, monthly figures (in SEK).

- Number of employed in the Stockholm County, 1999-2008, quarterly figures (in thousands).

- $\quad$ The average price of 95-octan gasoline, 1999-2008, monthly figures (in SEK).

- The supply of subway, 1999-2008, yearly figures (in kilometers).

- $\quad$ The population in the Stockholm County, 1999-2008, yearly figures (in thousands).

- Income from employment in Stockholm County, 1999-2008, yearly figures (in thousands). 


\subsubsection{Sample description}

Table 3 presents the descriptive statistics of the variables employed in the regression models.

Table 2 - Descriptive statistics of the variables used in regressions

\begin{tabular}{lrrrrr}
\hline Variable & N & Minimum & Maximum & Mean & Std. Deviation \\
\hline Peak & 120 & 140 & 795 & 503 & 135 \\
Off-peak & 120 & 185 & 710 & 473 & 107 \\
Price of 30 Day Card & 119 & 400 & 690 & 538 & 85 \\
Employed & 119 & 870 & 1022 & 940 & 34 \\
Petrol price & 119 & 7,8 & 13,9 & 10,3 & 1,4 \\
Supply & 119 & 87 & 94 & 90 & 2 \\
Income & 119 & 200 & 275 & 240 & 22 \\
Population & 119 & 1803 & 1981 & 1885 & 55 \\
\hline
\end{tabular}

In the sample description one can see that there is a total of 120 observations, more specifically monthly data over the ten year period. The explanatory variables are lagged one period. Therefore, there will be one missing observation for all variables. The reason for using lags is the assumption that travel will not be affected in the same period as a change in any of the lagged parameters occurs, but the month after in accordance with Balcombe et al. (2004).

When studying the standard deviation for the peak-period (135) and the off-peak period (107) in relation to the mean (503 and 473, respectively), it is clear that the variation in the data is noticeable. When decomposed into four different time periods (06:00 - 09:00, 09:00 - 15:00, 15:00 - 18:00, and 18:00 - 24:00), it is interesting to note that the variation still remains, see Table 3.

Table 3 - Descriptive statistics - number of passengers in four different time periods

\begin{tabular}{crrrrr}
\hline Time period & N & Minimum & Maximum & Mean & Std. Deviation \\
\hline 06:00-09:00 & 120 & 60 & 365 & 239 & 69 \\
09:00-15:00 & 120 & 105 & 415 & 282 & 67 \\
15:00-18:00 & 120 & 80 & 430 & 264 & 67 \\
18:00-24:00 & 120 & 80 & 295 & 191 & 41 \\
\hline
\end{tabular}




\subsubsection{The quality of the data}

The variation in the number of passenger variable may have been smaller if the data had been available on a more detailed level in terms of narrower time periods. For example, the period 18:00 - 24:00 may not be an off-peak period which is indicated by the large maximum of this period. This concern is solidified as Olsson, Tegnér and Gustafsson (2000) define the peakperiod as 07:00 - 09:00.and 16:00 - 19:00, and the off-peak as all other hours, indicating that 18:00-19:00 should not be in the off-peak period. However, SL has however not measured the travelling patterns in such detail, and therefore no such data is available.

Another concern with the data is that it is not on an individual level which makes it impossible to track the travelling patterns of specific individuals. An assumption made in the model is that the passengers react only to the different prices and not to the effects of the difference in pricing policies that SL have had. For this to hold, this implies that the passengers only travel within the central zone (subway), which has been unaffected by the change from flat rate to zone-pricing policies. If this is not the case, the price parameter does not display the cost of travelling correctly will therefore be misleading.

Many people commute to work from outside the central zone and their decisions are thus affected by the difference in pricing policies. However, due to limitations in SL's data collection this is the closest one can get to getting reliable results and this assumption has to be made.

There have been trade-offs with regards to the collected data on employment, income and population. The reason for this is that regional data is reported with a lower frequency (quarterly or yearly data) than national data (monthly or quarterly). However, the national data is of less relevance than the regional data. As mentioned, the choice has been made to prioritize relevancy over the number of observations in this study.

\subsection{The dependent variable}

The dependent variable in the analysis is the number of passengers travelling in the subway. The data is collected on a monthly basis by manual observations at large intersections; Gullmarsplan, Alvik, Liljeholmen, Östermalmstorg and Västra Skogen (Stockholm Public 
Transport, 2008). From these observations the total number of passengers travelling in the subway is estimated. The estimates are reported in four time periods; 06:00 - 09:00, 09:0015:00, 15:00 - 18:00, 18:00 - 24:00. In this study, the periods are combined into a peakperiod (06:00 - 09:00 and 15:00 - 18:00) and an off-peak period (09:00 - 15:00 and 18:00 24:00). These periods are chosen to come as close as possible to the SL peak- and off-peak periods defined by Olsson, Tegnér and Gustafsson (2000).

$$
\begin{gathered}
\text { Number of passengers } \\
\text { Number of passengers } \\
\text { 15:00-18:00 } \\
\text { Number of passengers }_{\text {06:00 }-09: 00}+ \\
\text { Number of passengers }_{\text {Off-peak }}=\text { Number of passengers }_{09: 00-15: 00}+ \\
\text { Number of passengers } \\
\text { 18:00 - 24:00 }
\end{gathered}
$$

\subsection{The explanatory variables}

In the analysis, there are in total 28 explanatory variables, where one is the price variable of the 30-day travel card and the remaining are control variables. The control variables are additional factors that could have an effect on the number of passengers and are therefore included in the regression in order to isolate the effect of the price variable.

The prices over the period 1999-2008 were provided by SL. The data has been checked by online searches to ensure that there is no mistyping.

In the study, short-term employment is used as a proxy for employment as there is a lag in the reporting of employment. However, data on short-term employment is up to date and gives relatively secure information on a regional level. The short-term data is collected via questionnaires sent to companies (Statistics Sweden, 2010).

Income from employment is used as a proxy for income. Disposable income would be a more accurate data-source for income, but is not available on the regional level making income of employment, which is reported on the regional level, a more reliable source of data.

The price of petroleum is collected from the petroleum company OKQ8. It is a monthly average on the price of the 95 octane petroleum in Sweden. 


\subsection{Dummies}

\subsubsection{Monthly dummies}

As the time series in this study is monthly data it is reasonable to believe that there are seasonal patterns. Studying the bar graph in Figure 4 it is evident that there is a seasonal pattern in the number of passengers travelling with SL. When there is a seasonal factor in a time series it is usually desirable that it is removed so that one can concentrate on other components (Gujarati, 2003).

There are a number of ways to handle a seasonal component. In this study, monthly dummies have been used to handle the seasonal pattern. Each month has been given a dummy except January that will serve as the reference month. If there is a seasonal effect in a given month then its dummy will be statistically significant.

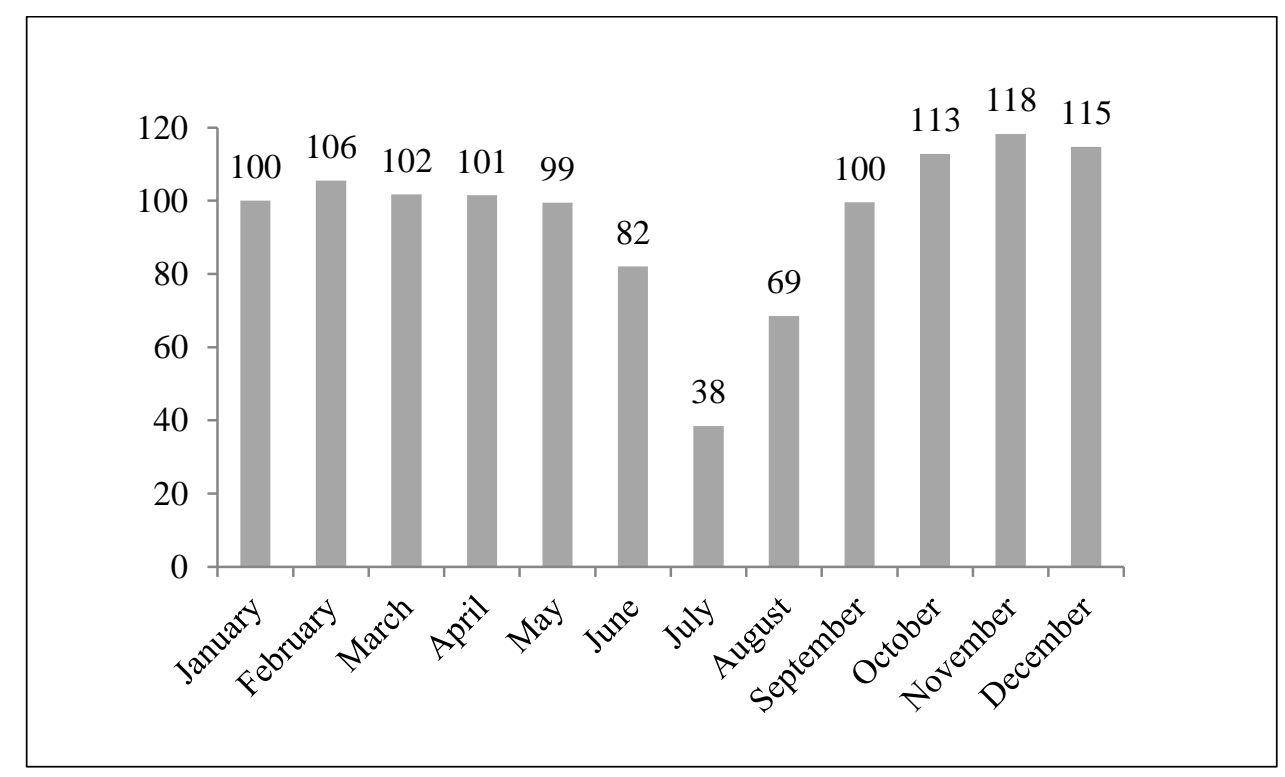

Figure 4 - average number of passengers travelling by subway per month ${ }^{9}$

\footnotetext{
${ }^{9}$ January is indexed to 100 . Source: Stockholm Public Transport (2008).
} 


\subsubsection{Interaction dummies}

In order to see if price changes have different effects depending on the month, interaction dummies are added in the regression. This helps isolate the general effect of price on the demand for travel to the price parameter.

\subsection{Handling the data set}

\subsubsection{Methodology}

An initial collection of variables was made in order to ensure that significant variables for the studied sample were used in the regression. Thereafter, the relationship between the number of passengers and the explanatory variables was studied using two regression models, one for the peak-period, and one for the off-peak period. In both regressions, a backwards regression model has been used. This method iterates the regression leaving the statistically significant variables (Edlund, 2007). However, there are risks associated with this method in SPSS, which is why both regressions also have been tested manually, using the SPSS enter method. This complements the backward model and certifies the statistical reliability of the findings (Edlund, 2007).

\subsubsection{Adjustments of the collected data}

Concerning the collection of data on explanatory variables, there are large differences in the time intervals in which the data is reported. When calculating the cost of traveling, some assumptions have been made, as described below:

- The explanatory variables are lagged one period. This is since it is assumed that a change in any of the explanatory variables will not have an effect on the number of passengers in the same period as it occurs.

- The data on employment, supply of subway, income and population in the Stockholm area are reported on a yearly basis except for employment, which is reported quarterly. Therefore, these variables have been manually recalculated as a linear trend between the observations. 


\section{Results}

\subsection{Regression model to test the hypothesis}

In order to test the null-hypothesis, a regression model has been set up and the model is tested for the peak- and the off-peak period, separately. The regression models used to test the hypothesis are presented below.

$$
\begin{gathered}
\text { Number of passangers }{ }_{\text {PEAK }}=\text { cons }+\beta_{1} \text { Price }_{30 \text { day }}+\beta_{2} \text { Employed }+ \\
\beta_{3} \text { Petrol }+\beta_{4} \text { Supply }+\beta_{5} \text { Population }+\beta_{6} \text { Income }+\delta_{1} \text { Feb } \ldots+\delta_{11} \text { Dec }+ \\
\beta_{7} \text { Price }_{30 \text { day }} * \text { Feb } \ldots+\beta_{8} \text { Price }_{30 \text { day }} * \text { Dec }+\mathrm{e} \\
\text { Number of passangers } \\
\text { OFF-PEAK }=\text { cons }+\beta_{1} \text { Price }_{30 \text { day }}+ \\
\beta_{2} \text { Employed }+\beta_{3} \text { Petrol }+\beta_{4} \text { Supply }+\beta_{5} \text { Population }+\beta_{6} \text { Income }+ \\
\delta_{1} \text { Feb } \ldots+\delta_{11} \text { Dec }+\beta_{7} \text { Price }_{30 \text { day }} * \text { Feb } \ldots+\beta_{8} \text { Price }_{30 \text { day }} * \text { Dec }+\mathrm{e}
\end{gathered}
$$

\begin{tabular}{|c|c|}
\hline Variable name & Description \\
\hline Price $_{30 d a y}$ & The price of 30-day travel card. Lagged one period. \\
\hline Employed & $\begin{array}{l}\text { Number of employed in the Stockholm County. } \\
\text { Lagged one period. }\end{array}$ \\
\hline Petrol & $\begin{array}{l}\text { The average price of } 95 \text { octane petrol. Lagged one } \\
\text { period. }\end{array}$ \\
\hline Supply & $\begin{array}{l}\text { The supply of subway measured in kilometers. } \\
\text { Lagged one period. }\end{array}$ \\
\hline Population & $\begin{array}{l}\text { Population in Stockholm County. Lagged one } \\
\text { period. }\end{array}$ \\
\hline Income & $\begin{array}{l}\text { Income from employment in Stockholm County. } \\
\text { Lagged one period. }\end{array}$ \\
\hline Feb - Dec & Monthly dummy variables. \\
\hline Price $_{30 \text { day }}{ }^{*}$ Feb - Price 30 day ${ }^{*}$ Dec & Interaction dummies for price and months. \\
\hline
\end{tabular}

Table 4 - Description of variables 
In SPSS the backward method is used to test the initial model and to find the variables that are significant. The variables that are significant on a 5\% significance level in the peak- period are the 30-day travel card price parameter, employment, income and population. In the offpeak period, the same variables as in the peak-period are significant, except income. The results are presented in Table 5 and 6 . The adjusted $\mathrm{R}^{2}$ for the peak-period and off-peak period are 0.9613 and 0.9506 , respectively ${ }^{10}$. This can be interpreted as that the regressions explain 96.13 percent and 95.06 percent of the variance of the number of passengers in the Stockholm subway.

The results from the final regressions show that the price parameter of the 30-day travel card has a negative effect on the number of passengers. The negative effect of the price parameter is lower in the peak-period (-0.19) than in the off-peak period $(-0.27)$. The effect of employment is positive in both the peak-period (0.87) and the off-peak period (0.66). The results indicate that the income has a negative effect on the number of passengers in the peakperiod $(-2.90)$ but in the off-peak period it does not have an effect, as it is statistically insignificant. The population has a positive effect in both peak-period (1.52) and off peakperiod (0.52). In addition, there are a number of dummy variables and interaction dummies that are significant. There are more significant variables in the off-peak period indicating that the seasonal factors have a greater impact in that period.

\footnotetext{
${ }^{10}$ In this study the adjusted $\mathrm{R}^{2}$ will be reported as it is adjusted for the degrees of freedom associated with the sums of squares entering into the model. More directly, the $\mathrm{R}^{2}$ is adjusted so that it does not get a falsely high value due to that the model consists of many explanatory variables (Gujarati 2003).
} 
Table 5 - Estimation results - peak period $^{11}$

\begin{tabular}{|c|c|c|c|c|}
\hline Variable & First reg. & Robust Std Error & Final est. reg. & Robust Std Error \\
\hline Price of 30 day card & -0.36 & 0.16 & -0.19 & 0.10 \\
\hline Employed & 0.83 & 0.18 & 0.87 & 0.14 \\
\hline Petrol price & 5.87 & 5.63 & - & - \\
\hline Supply & 0.23 & 2.80 & - & - \\
\hline Income & -3.20 & 1.26 & -2.90 & 1.10 \\
\hline Population & 1.53 & 0.41 & 1.52 & 0.36 \\
\hline dfeb & -32.67 & 71.47 & - & - \\
\hline dmars & -117.78 & 91.53 & - & - \\
\hline dapril & -181.56 & 81.82 & - & - \\
\hline dmay & -173.47 & 74.41 & -30.61 & 8.65 \\
\hline djune & -250.35 & 82.74 & -136.75 & 9.61 \\
\hline djuly & -401.54 & 81.26 & -378.89 & 9.26 \\
\hline daug & -312.00 & 73.28 & -210.03 & 7.92 \\
\hline dsep & -268.25 & 98.72 & -178.93 & 71.85 \\
\hline doct & -117.85 & 130.94 & - & - \\
\hline dnov & -110.57 & 101.30 & - & - \\
\hline ddec & -50.13 & 84.28 & - & - \\
\hline dfeb30 & 0.10 & 0.15 & 0.05 & 0.01 \\
\hline dmars 30 & 0.21 & 0.19 & - & - \\
\hline dapril30 & 0.31 & 0.17 & - & - \\
\hline dmay30 & 0.25 & 0.16 & - & - \\
\hline djune30 & 0.20 & 0.17 & - & - \\
\hline djuly30 & 0.03 & 0.17 & - & - \\
\hline daug30 & 0.17 & 0.15 & - & - \\
\hline dsep30 & 0.45 & 0.18 & 0.30 & 0.12 \\
\hline $\operatorname{doct} 30$ & 0.29 & 0.24 & 0.08 & 0.02 \\
\hline dnov30 & 0.34 & 0.20 & 0.14 & 0.02 \\
\hline ddec30 & 0.16 & 0.16 & 0.07 & 0.02 \\
\hline
\end{tabular}

${ }^{11}$ The table shows the first regression (where all variables are included) and the final estimates regression (where only statistically significant variables are included). The variables are significant on a five percent significance level. The final estimated regression has an adjusted $\mathrm{R}^{2}$ of 0.9613 . 
Table 6 - Estimation results - off-peak period $^{12}$

\begin{tabular}{|c|c|c|c|c|}
\hline Variable & First reg. & Robust Std Error & Final est. reg. & Robust Std Error \\
\hline Price of 30 day card & -0.41 & 0.16 & -0.27 & 0.08 \\
\hline Employed & 0.74 & 0.19 & 0.66 & 0.13 \\
\hline Petrol price & 1.62 & 5.29 & - & - \\
\hline Supply & 3.07 & 2.73 & - & - \\
\hline Income & -2.16 & 1.17 & - & - \\
\hline Population & 1.13 & 0.38 & 0.52 & 0.17 \\
\hline dfeb & -16.75 & 71.23 & - & - \\
\hline dmars & -77.59 & 84.30 & - & - \\
\hline dapril & -182.44 & 77.36 & - & - \\
\hline dmay & -140.56 & 75.86 & - & - \\
\hline djune & -217.76 & 74.82 & -72.59 & 9.23 \\
\hline djuly & -351.97 & 69.66 & -278.26 & 7.71 \\
\hline daug & -326.50 & 71.43 & -228.89 & 45.62 \\
\hline dsep & -225.62 & 88.30 & -130.57 & 67.64 \\
\hline doct & -150.42 & 111.73 & - & - \\
\hline dnov & -140.62 & 87.71 & - & - \\
\hline ddec & -4.76 & 71.17 & - & - \\
\hline dfeb30 & 0.11 & 0.15 & 0.05 & 0.02 \\
\hline dmars 30 & 0.17 & 0.17 & - & - \\
\hline dapril30 & 0.38 & 0.16 & - & - \\
\hline dmay30 & 0.28 & 0.16 & - & - \\
\hline djune30 & 0.29 & 0.16 & - & - \\
\hline djuly30 & 0.16 & 0.14 & - & - \\
\hline daug30 & 0.37 & 0.15 & 0.16 & 0.08 \\
\hline dsep30 & 0.41 & 0.17 & 0.21 & 0.11 \\
\hline $\operatorname{doct} 30$ & 0.40 & 0.20 & 0.10 & 0.02 \\
\hline dnov30 & 0.42 & 0.18 & 0.13 & 0.02 \\
\hline ddec30 & 0.18 & 0.14 & 0.14 & 0.02 \\
\hline
\end{tabular}

${ }^{12}$ The table shows the first regression (where all variables are included) and the final estimates regression (where only statistically significant variables are included). The variables are significant on a five percent significance level. The final estimated regression has an adjusted $\mathrm{R}^{2}$ of 0.9506 . 
The results from our regressions give the following final estimated models, the first for the peak-period and the second for the off-peak period:

$$
\begin{aligned}
& \text { Number of passangers }{ }_{\text {PEAK }}=\text { cons }+\beta_{1} \text { Price }_{30 \text { day }}+\beta_{2} \text { Employed }+ \\
& \beta_{3} \text { Income }+\beta_{4} \text { Population }+\delta_{1} \text { May }+\delta_{2} \text { June }+\delta_{3} \text { July }+\delta_{4} \text { Aug }+\delta_{5} \text { Sep }+ \\
& \beta_{5}\left(\text { Price }_{30 \text { day }} * \text { Feb }\right)+\beta_{6}\left(\text { Price }_{30 \text { day }} * \text { Sep }\right)+\beta_{7}\left(\text { Price }_{30 \text { day }} * \text { Oct }\right)+ \\
& \beta_{8}\left(\text { Price }_{30 \text { day }} * \text { Nov }\right)+\beta_{9}\left(\text { Price }_{30 \text { day }} * \text { Dec }\right)+e \\
& \text { Number of passangers }{ }_{\mathrm{OFF}-\mathrm{PEAK}}=\text { cons }+\beta_{1} \text { Price }_{30 \text { day }}+ \\
& \beta_{2} \text { Employed }+\beta_{3} \text { Population }+\delta_{1} \text { June }+\delta_{2} \text { July }+\delta_{3} \text { Aug }+\delta_{4} \text { Sep }+ \\
& \beta_{4}\left(\text { Price }_{30 \text { day }} * \text { Feb }\right)+\beta_{5}\left(\text { Price }_{30 \text { day }} * \text { Aug }\right)+\beta_{6}\left(\text { Price }_{30 \text { day }} * \text { Sep }\right)+ \\
& \beta_{7}\left(\text { Price }_{30 \text { day }} * \text { Oct }\right)+\beta_{8}+\left(\text { Price }_{30 \text { day }} * \text { Nov }\right)+\beta_{9}\left(\text { Price }_{30 \text { day }} * \text { Dec }\right)+e
\end{aligned}
$$

The results indicate that the price parameter is significant in both regressions. This result makes it possible to reject the null-hypothesis, that the price parameter does not explain the number of passengers. The effect of the price parameter also differs in the peak- and off-peak regressions, indicating differences in elasticities for the periods. This is line with what the results from previous studies.

\subsection{Issues in estimation}

In the previous section the null-hypothesis has been tested to see if it can be rejected. The regressions run on the peak- and off-peak period indicate that price affects the numbers of passengers in both the peak- and off-peak period. Before analyzing these results, the regression model has to be tested to verify the statistical reliability of the results. Two tests are conducted; a test for multicollinearity and test for serial correlation. The concern of heteroscedasticity has been eliminated by using robust standard errors in all regressions conducted in the study (Gujarati, 2003). 


\subsubsection{Multicollinearity}

The model is tested for multicollinearity as one wants to ensure that there is no correlation between two or more of the explanatory variables. If there is correlation, this will affect the outcome of the regression as the collinear variables would hold the same information about the dependent variables. Further, if multicollinearity is found, the standard errors of the affected coefficients tend to be relatively large. To test the final estimated regression for multicollinearity, the Variance-inflating factor (VIF) has been used. If the VIF indicates high values (VIF>10) then there is reason for concern regarding multicollinearity (Gujarati, 2003).

The VIF-test was conducted on the final estimated regression. A few variables were highly correlated resulting in high values in the VIF-test and therefore a new regression has to be done where the variables with high values are omitted. This is done stepwise meaning that one variable is omitted at a time and thereafter a backward regression is run to see the new outcome. This is done until only significant variables with acceptable VIF values remain $(\mathrm{VIF}<10)$. This has to be done for both the peak- and off-peak period and the adjusted regressions are presented in Table 7 . The adjusted regression for the peak-period has an adjusted $\mathrm{R}^{2}$ of 0.955 and for the off-peak period the corresponding value is 0.938 .

\subsubsection{Serial correlation}

The Durbin-Watson test is used to detect any signs of serial correlation between the residuals in the regression model. If there is serial correlation in the data set, the standard errors of the affected variables tend to be overestimated. To test for serial correlation, the Durbin Watson test is commonly used. The test presents a value between zero and four. If the result of the test is equal to two there is no sign of serial correlation. (Gujarati, 2003)

The Durbin-Watson value obtained for the peak-period final estimated regression and the corresponding for the off peak period were 1.751 and 1.692. When testing the adjusted regressions, the corresponding value is 1.675 for the peak-period and 1.681 for the off-peak period. Common practice regards a value below one as critical and therefore there are no signs of critical autocorrelation in our models (Gujarati, 2003). 
Table 7 - Estimation results - peak and off-peak periods - adjusted for multicollinearity ${ }^{13}$

\begin{tabular}{|c|c|c|c|c|c|c|}
\hline Variable & $\begin{array}{l}\text { Adj. } \\
\text { Peak }\end{array}$ & $\begin{array}{r}\text { Robust Std } \\
\text { Error }\end{array}$ & VIF & $\begin{array}{r}\text { Adj. Off- } \\
\text { peak }\end{array}$ & $\begin{array}{r}\text { Robust Std } \\
\text { Error }\end{array}$ & VIF \\
\hline Constant & -450.20 & 104.44 & & -654.88 & 268.23 & \\
\hline Price 30 day card & -0.16 & 0.06 & 4.50 & -0.13 & 0.06 & 5.39 \\
\hline Employed & 1.03 & 0.13 & 2.85 & 0.89 & 0.15 & 3.52 \\
\hline Petrol price & 12.32 & 4.65 & 6.12 & 8.47 & 4.52 & 6.47 \\
\hline Supply & - & & - & 3.31 & 2.44 & 2.07 \\
\hline Income & - & & - & - & & - \\
\hline Population & - & & - & - & & - \\
\hline dfeb & 31.95 & 8.72 & 1.23 & 33.27 & 8.09 & 1.16 \\
\hline dmars & - & & - & - & & - \\
\hline dapril & - & & - & - & & - \\
\hline dmay & -36.03 & 8.95 & 1.25 & - & & - \\
\hline djune & -143.85 & 9.35 & 1.27 & -77.53 & 8.65 & 1.18 \\
\hline djuly & -385.70 & 10.90 & 1.27 & -282.37 & 8.56 & 1.18 \\
\hline daug & -217.26 & 9.45 & 1.28 & -145.71 & 9.49 & 1.19 \\
\hline dsep & -23.74 & 17.20 & 1.27 & -21.16 & 14.62 & 1.18 \\
\hline doct & - & - & - & - & - & - \\
\hline dnov & - & - & - & - & - & - \\
\hline ddec & 39.49 & 8.32 & 1.26 & 81.85 & 7.14 & 1.19 \\
\hline dfeb30 & - & - & - & - & - & - \\
\hline dmars30 & - & - & - & - & - & - \\
\hline dapril30 & - & - & - & - & - & - \\
\hline dmay30 & - & - & - & - & - & - \\
\hline djune30 & - & - & - & - & - & - \\
\hline djuly30 & - & - & - & - & - & - \\
\hline daug30 & - & - & - & - & - & - \\
\hline dsep30 & - & - & - & - & - & - \\
\hline $\operatorname{doct} 30$ & 0.07 & 0.02 & 1.26 & 0.09 & 0.02 & 1.17 \\
\hline dnov30 & 0.14 & 0.02 & 1.26 & 0.13 & 0.02 & 1.18 \\
\hline ddec 30 & - & - & - & - & - & - \\
\hline
\end{tabular}

${ }^{13}$ The VIF-values indicate that there is little correlation between the variables in the adjusted models. The adjusted R2 for the peak-period is 0.9547 and 0.9376 for the off-peak period. 


\subsection{Calculations}

\subsubsection{Price elasticities of demand for the peak- and off-peak period}

Since the price parameter is significant in the regressions, it have been used to calculate elasticities in order to be able to analyse which prices SL should pick according to the Ramsey pricing strategy to maximize profits and minimize welfare loss. The estimated price elasticities of demand the peak- and off-peak period are presented in Table 8.

The elasticities are calculated based on three different figures. To begin with, the elasticities are calculated based on the beta coefficients from the final estimated regression. Thereafter, the elasticities are calculated based on the coefficients from the adjusted regression which has been adjusted for multicollinearity. Finally, elasticities are calculated on the mean of the coefficients from these two regressions. The reason for presenting three separate figures (final estimated regression, adjusted regression, and mean) is because when the model is adjusted for multicollinearity, some relevant variables with the same trend (which causes multicollinearity) may have been omitted affecting the results. Therefore, it is difficult to determine which model that is most relevant wherefore three figures are presented in order to get as accurate a result as possible.

The peak-period elasticities vary between -0.14 to -0.20 while the off-peak period elasticities vary between -0.16 to -0.31 . The difference between the periods is greater in the final estimated regression where the off-peak period elasticity is 55 percent higher than the elasticity of the peak-period. In the adjusted regression the elasticity of the off-peak period is 14 percent higher than that of the peak-period.

Table 8 - Estimated price-elasticities - peak- and off-peak periods ${ }^{14}$

\begin{tabular}{lrr}
\hline Model & Peak & Off-peak \\
\hline Final estimated regression & -0.20 & -0.31 \\
Adjusted regression & -0.14 & -0.16 \\
Mean & -0.17 & -0.23 \\
\hline
\end{tabular}

${ }^{14}$ Table showing the elasticities for peak- and off-peak period from the final estimated regression and the adjusted regression. A mean of both the regressions is also presented. 


\subsubsection{Ramsey prices}

The Ramsey prices for the two periods are presented in Table 9. The elasticities from the final estimated regression indicate that SL should set the price for peak-period about 70 percent higher than that of the off-peak period to maximize profit (See formula 2.1). With elasticities from the adjusted regression, the corresponding figure indicates a 20 percent higher price in the peak-period than in the off-peak period. Finally, the mean elasticities indicate that the peak-period price should be 50 percent higher than the off-peak period price. However, the exact level depends on the marginal cost, which in this study is assumed to be equal in both periods in accordance with common practice on calculations of Ramsey prices (Besanko, 2001).

Table 9 - Relation between price in peak- and off-peak period according to Ramsey-pricing ${ }^{15}$

\begin{tabular}{lr} 
Model & P $_{\text {PEAK }} /$ P $_{\text {OFF-PEAK }}$ \\
\hline Final estimated regression & 1.7 \\
Adjusted regression & 1.2 \\
Mean & 1.5 \\
\hline
\end{tabular}

\section{a. Effect of Ramsey pricing on the number of passengers and revenue}

To better understand the effect of using Ramsey pricing on the total number of passengers, the distribution of passengers in the peak- and off-peak period as well as the effect on total revenue, two simulations are made. The simulations are based on the final estimated regression and the adjusted regression and the results are presented in Figures 5 and 6.

In Simulation 1, only the price in the peak-period is increased in order to meet the relative prices as suggested by the Ramsey pricing rule (1.2 and 1.7 for the final estimated regression and adjusted regression, respectively). The off-peak period price is thus unchanged. In

\footnotetext{
${ }^{15}$ Table showing the relationship between price in peak- and off-peak period according to Ramseypricing. It is calculated using the elasticities from the final estimated regression, the adjusted regression and a mean of the regressions.
} 
Simulation 2, the price is increased in the peak-period and decreased in the off-peak period in the same proportions, to meet the same Ramsey relative prices.

The simulations from both the final estimated regression and the adjusted regression (Figures 5 and 6) demonstrate that the revenue is maximized in Simulation 1 (123 and 109 for the final estimated regression and the adjusted regression, respectively). However, in this scenario, both charts also display a reduction in the total number of passengers.

When increasing the peak-period prices and decreasing the off-peak prices with the same proportions (Simulation 2) both the final estimated regression and the adjusted regression indicate less passengers in the peak-period (95 and 98, respectively) as well as an increase in passengers in the off peak period (109 and 102, respectively). They also show a constant or increasing total number of passengers (101 and 100) and total revenue (101 and 100).

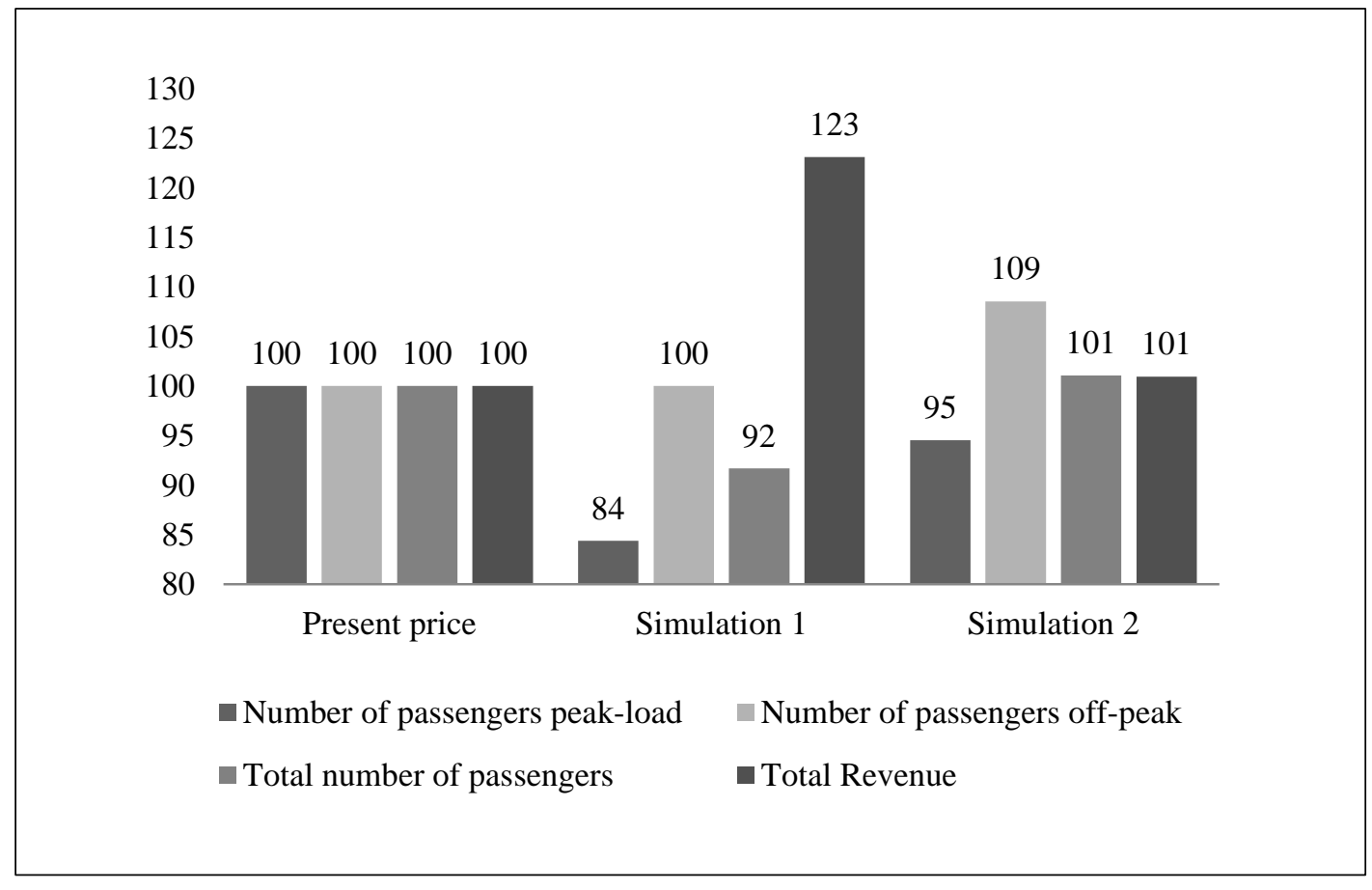

Figure 5 - estimated effect of Ramsey pricing - estimated regression ${ }^{16}$

\footnotetext{
${ }^{16}$ This chart shows the effect of Ramsey pricing on the number of passengers and total revenue indexed to present figures for the final estimated regression. In Simulation 1, only the price in the peak-period is increased and in Simulation 2, the price is increased in the peak-period and decreased in the off-peak period in the same proportions, to meet the Ramsey relative prices.
} 


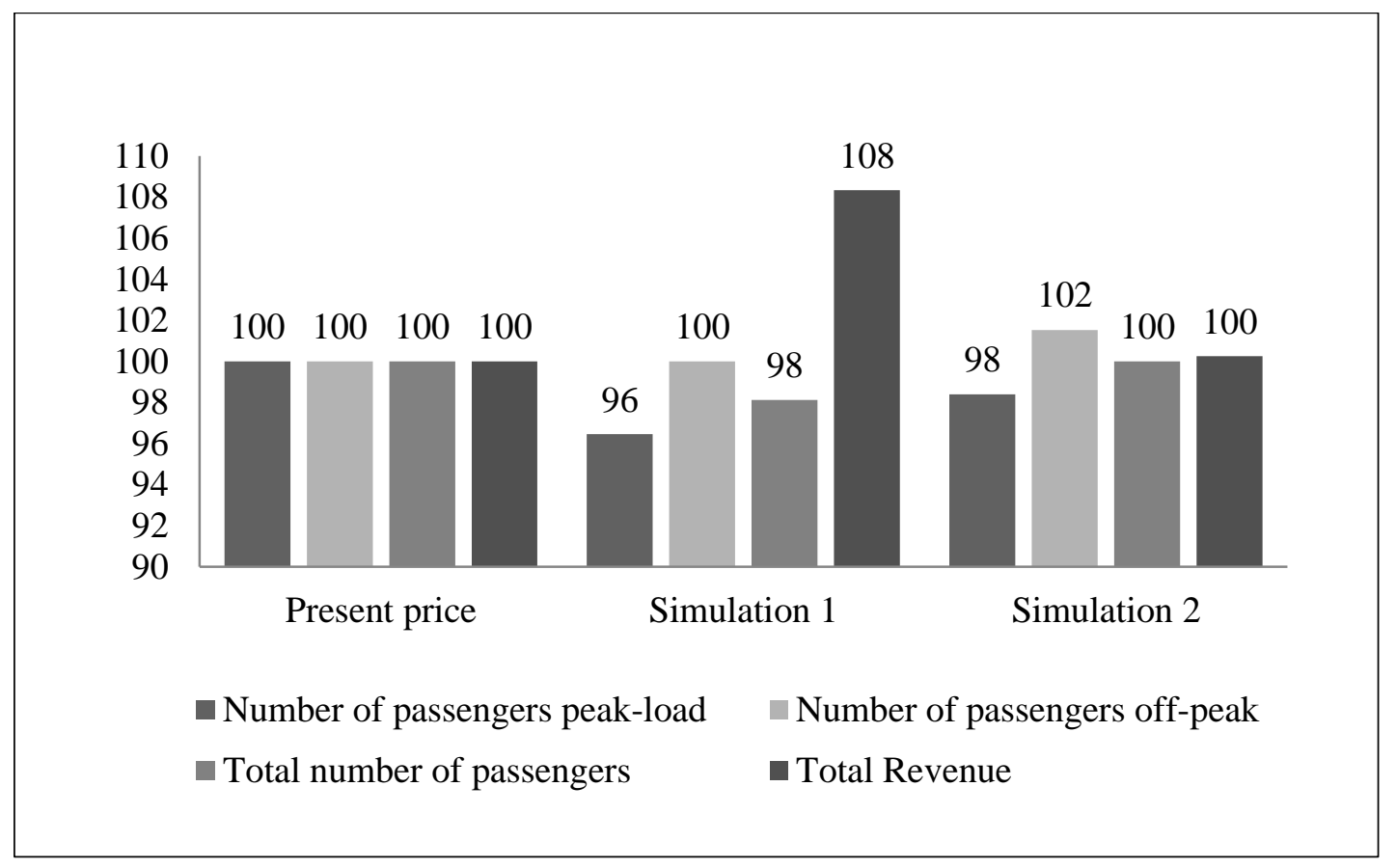

Figure 6 - estimated effect of Ramsey pricing - adjusted regression ${ }^{17}$

\section{Conclusion}

This paper studied how the price affects the demand for public transport in the peak- and offpeak period in the public transport in Stockholm, and how differences in price elasticities of demand in the peak- and off-peak period can enable an increase in revenues and the total number of passengers through price discrimination. The econometric model employed was tested, and was found that the final estimated regression suffered from multicollinearity. The model was corrected for this matter. However, the results differ substantially between the uncorrected and corrected models. The reason for this is because when the model is adjusted some relevant variables with the same trend (which causes multicollinearity) may have been omitted affecting the results.

Our results can be summarized in the following way. First, on the price-elasticities of demand: the elasticities in this study reflect the short-run effects of how the changes in price

\footnotetext{
${ }^{17}$ This chart shows the effect of Ramsey pricing on the number of passengers and total revenue indexed to present figures for the adjusted regression. In Simulation 1, only the price in the peakperiod is increased and in Simulation 2, the price is increased in the peak-period and decreased in the off-peak period in the same proportions, to meet the Ramsey relative prices.
} 
affects the number of passengers. Comparing the short-run elasticities of previous research to those of this study, it is possible to conclude they are similar, very close to the international mean of -0.21 (The peak-period has a mean elasticity of -0.17 and off-peak period has a mean of -0.23).

The results point in the same direction as previous international studies; that the elasticities of demand are inelastic. This means that SL has the opportunity to maximize their profit by charging a higher price which also will lower the number of passengers in the peak-period. The intention is not to lower total number of passengers travelling with SL but rather smoothing the demand curve so that more passengers travel in the off-peak period. This could help SL to overcome some of their most crucial congestion problems as it is hard for them to put more trains in to traffic during the peak-hours.

It is also theoretically more economically efficient for SL to price differentiate as they would then not increase average costs by higher fixed costs that most likely would be the result with an expansion of the subway. It is, however, important to keep in mind that the long-run elasticities generally are higher than those in the short-run, which is indicated by previous studies. Such effects are not analyzed in this study but should be considered by SL when considering differentiated prices on their tickets.

Previous research has not focused on how the elasticities differ between peak- and off-peak period when simulating the effect of peak-load pricing on the number of passengers in the urban transportation of Stockholm. However, the general result in the international studies that do classify the elasticities into peak and off-peak periods is that elasticities are twice as high in the off-peak period compared to the peak-period. In this study the result varied between the final regression and the final regression corrected for multicollinearity. In the former, the elasticity in the off-peak was 55 percent higher than in the peak-period. In the latter, it was only 14 percent higher. On average the elasticities were 35 percent higher in the off-peak than the peak-period indicating a result which is lower than result from the international studies. One possible explanation for this is of the lack of detail in the data on the number of passengers, which may have resulted in peak-period passengers being defined as off-peak and thus lowering the elasticity of demand on the latter. 
Second, regarding the Ramsey pricing. The results of the Ramsey pricing rule indicate that SL needs to increase their prices on peak-period services in order to maximize profits. The results from the final regression indicate an optimal price which is 70 percent higher in the peakperiod than in the off-peak period. The corresponding results from the adjusted model point to a price in the peak-period which is 20 percent higher than in the off-peak period.

If SL simply wanted to maximize profits, our simulations suggest that they should raise prices in peak-period by 70 percent. This would result in a revenue increase of 23 percent according to the final regression model and 9 percent according to the adjusted model. This policy also lowers the number of passengers in the peak-period, which reduces the peak-load problem and need for investments in capacity which is unutilized during the off-peak periods. However, this pricing policy is unlikely since SL also has the goal to increase the number of passengers when implementing a new pricing policy. This pricing policy would according to our simulations result in a reduction of passengers by 8 and 2 percent for the final regression model and adjusted model, respectively, thus making it unlikely.

The pricing policy in Simulation 2, where the peak-period prices are increased and the offpeak prices are decreased in the same proportions ( 26 percent for the final estimated model and 9 percent for the adjusted models) is a more suitable pricing policy. Both the final estimated regression and the adjusted regression suggest less passengers in the peak-period (95 and 98, respectively) as well as an increase in passengers in the off peak period (109 and 102, respectively). The simulation also indicates a constant or increasing total number of passengers (101 and 100) and total revenue (101 and 100). This pricing policy would therefore meet the goal of increased travelling as well as redistribute passengers from the peak-period, with excessive demand, to the off-peak periods. It also leaves revenues higher or unaffected, which is of importance due to the trend of decreasing tax funding levels within the public transport of Stockholm.

The results of the study indicate that SL can dampen the peak-load problem by redistributing passengers from the peak-period to the off-peak period and at the same time maintaining or even increasing their market shares and revenue. It would be interesting to see similar studies that take the difference in price elasticities of demand in the peak- and the off-peak period into account. 
Finally, with respect to suggestions for future research. For future research it is suggested that a study is conducted with more detailed data. This is both with regards to how narrow the time period on the number of passengers is calculated as well as the number of variables collected. Preferably, individual data on travelling should be collected in order to find crossprice elasticities to enable an analysis of the effect of a raise in price in the peak-period on the number of passengers in the off-peak period. This type of study was not possible with the available data, but the SL Access card gives an opportunity to conduct this study in the future. The Access card enables the collection of detailed information on traveling patterns of individuals which can be studied in a way that has not been possible until now. The Access card also opens up for natural experiments where SL can give selected individuals rebates on off-peak traveling and analyze what effect this would have.

Another unexplored topic in this study is the welfare effects of redistributing passengers from the peak-period to the off-peak period. A study focusing on which externalities and social effects this would have would be a good complement to earlier studies of peak-load pricing.

In summary, it can be said that the study complements earlier international studies of peakload pricing and gives an indication as to how changes in price affects the number of passengers in the peak- and off-peak period in the public transport in Stockholm. Since there is a lack of studies of this type on the public transport in Stockholm, the authors believe that more research is needed in this field as there are yet many topics to be analyzed and explored.

\section{References}

Balcombe, R., Mackett, R., Paulley, N., Preston, J., Shires, J., Titheridge, H., Wardman, M. and White, P. (2004) The demand for public transport: a practical guide, TRL593. Available at www.demandforpublictransport.co.uk.

Baumol, W. J., (1995) Modified regulation of telecommunications and the public-interest standard, In: Bishop, M., Kay, J. and Mayer, C. (eds.) The Regulatory Challenge. Oxford: Oxford University Press.

Baumol, W. J. and Bradford, D. F. (1970) Optimal departures from marginal cost pricing. American Economic Review, vol. 60, n. 3, pp. 265-283.

Besanko, D., (2001) Microeconomics - an integrated approach. $1^{\text {st }}$ edition, John Wiley \& Sons.

Boituex, M. (1960), Peak-load pricing. Journal of Business, vol. 33, n. 2, pp. 157-179.

Charles River Associates (1997) Building transit ridership: an exploration of transit's market share and the public policies that influence it, Transit Cooperative Research Program Report 27. 
Cummings, C. P., Fairhurst, M., Labelle, S. and Stuart, D. (1989) Market segmentation of transit fare elasticities. Transportation Quarterly, vol. 43, n. 3, pp. 407-420.

Doi, M. and Allen, W. B., (1986) A time series analysis of monthly ridership for an urban rail rapid transit line. Transportation, vol. 13, n. 3, pp. 257-269.

Edlund, P-O. (1997) SPSS för Windows 95, Multipel regressionsanalys (version 7.5). Lund: Studentlitteratur.

Fearnley, N. (2004) Inventive pricing in urban public transport, Institution of Transport Economics, Oslo. Available at www.aetransport.org.

Gujarati, D. N., (2003) Basic econometrics, 4th edition. Boston: McGraw-Hill.

Higginson, M., (2002) Public transport finance, UTIP position statement, final version 11 - long version 30 .

Kessides, I. N. and Willig, R. D. (1995) Restructuring regulation of the rail industry for the public interest, Volume 1, World Bank Policy Research Working paper 1506, WB Private Sector Development Department.

LTI Consultants, Inc. and E. A. France and Associates (1988) Fare structure analysis. Prepared for the Chicago Transit Authority, Chicago, IL.

Mayworm, P. D., Lago, A. M., and McEnroe, J. M. (1980) Patronage impacts of changes in transit fares and services. Prepared for the Urban Mass Transportation Administration, Econometrics Incorporated, Bethesda, MD.

Nilsson, J-E. (1992) Second-best problems in railway infrastructure pricing and investment. Journal of Transport Economics and Policy, vol. 26, n. 3, pp. 245-259.

Olsson, Tegnér and Gustafsson (2000) Sl-taxan - 3 scenarier. Prepared by Transek for SL, Stockholm, Sweden.

Oum, T. H., Waters II, W. G. and Yong, J-S. (1992) Concepts of price elasticities of transport demand and recent empirical estimates: an interpretative survey. Journal of Transport Economics, vol. 26, n. 2, pp. 139-154.

Perloff, J. M. (2007) Microeconomics - theory and applications with calculus: international edition. $4^{\text {th }}$ edition. Boston, Mass.: Pearson Addison Wesley.

Pigou, A. C. (1929) The economic of welfare. $3^{\text {rd }}$ edition. London: Macmillan.

Pratt et al. (2000) Travelers response to transportation system changes, Interim Handbook, TCRP Web Document 12 (project $B-12$ ), available at www.trb.org.

Ramsey, F. P. (1927) A Contribution to the theory of taxation, The Economic Journal, vol. 37(145), 47-61.

Reinke, D. (1988) Recent changes in BART patronage. Transportation Research Board $67^{\text {th }}$ Annual Meeting, Washington, DC.

Statistics Sweden (2010) Arbetsmarknadsstatistiken på SCB. Brochure. Stockholm. Available at www.scb.se.

Stockholm Public Transport (2009) Annual report 2009. Brochure, Stockholm. Available at sl.se.

Stockholm Public Transport (2008) Fakta om SL och länet 2008. Brochure, Stockholm. Available at sl.se.

Stockholm Public Transport (2009) This is Stockholm Public Transport - a presentation of our activities. Brochure. Stockholm. Available at www.sl.se. 
Tegnér, G., (2002) SL:s resandeutveckling 1997-2001 - Komponentanalys. Prepared by Transek for SL, Stockholm.

Transek (2005) Fyra taxestrategier för SL - Utformning samt konsekvenser för resor, ekonomi och fördelning. Prepared by Transek for SL. Stockholm.

Vickrey, W. S. (1963) Pricing in urban and suburban transport, The American Economic Review, vol. 53, n. 2, pp. 452-465.

Wooldridge, J. M. (2009) Introductory econometrics - a modern approach, $4^{\text {th }}$ edition. Canada: South-Western Cengage Learning.

WSP Sverige AB (2009) Privata partners för bättre information på väg - Analys av samverkansmodeller för informationstjänster inom vägtrafiken. Prepared by WSP Group AB for $S L$, Stockholm. Available at www.sou.gov.se.

\section{Interview}

Damström, J., Head of Business Development at SL AB. 2009-11-13. 


\section{Appendix A - Five and Three zone model}

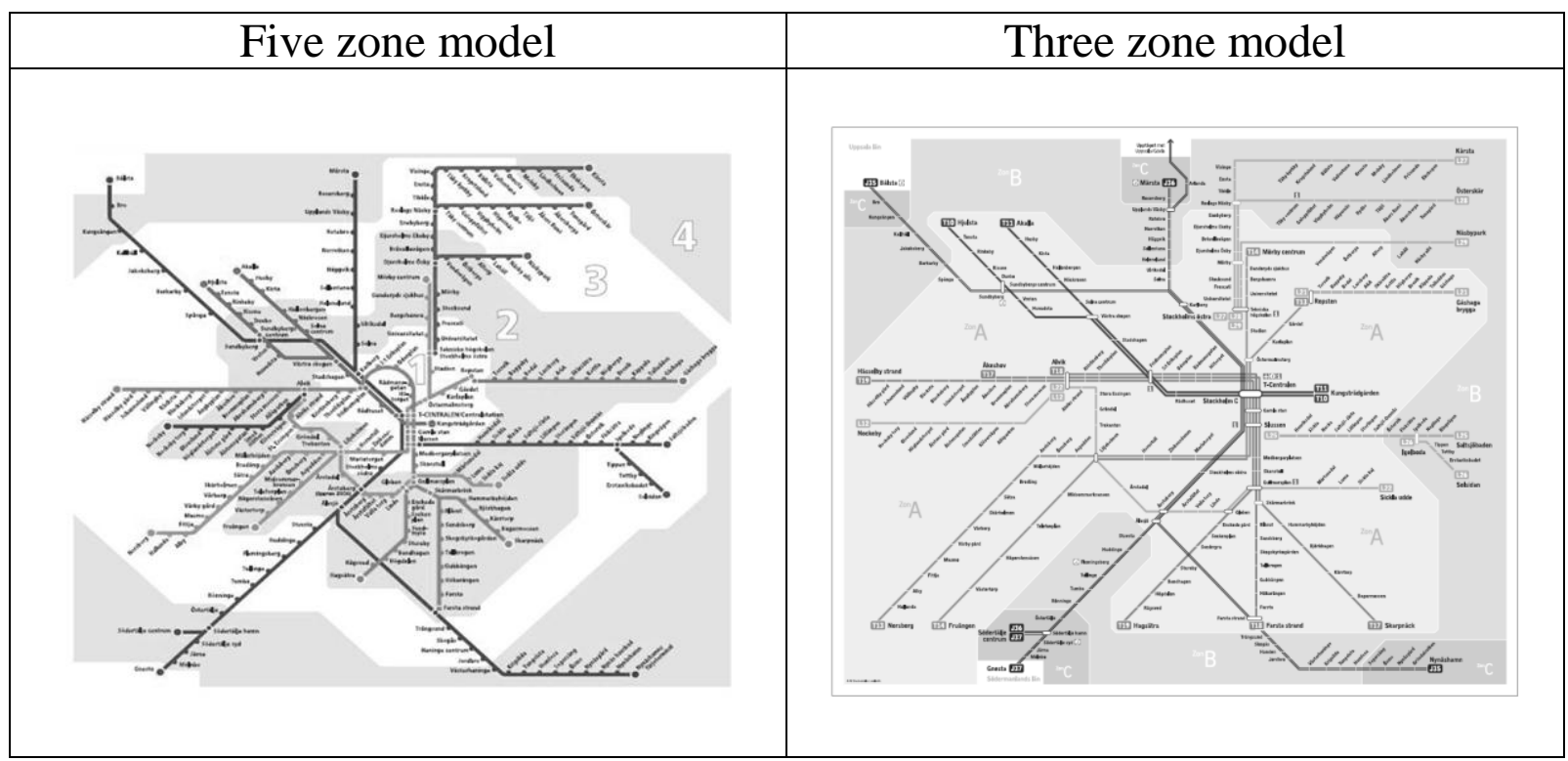




\section{Appendix B1 - First regression peak-period}

Number of obs

\begin{tabular}{lrrrrrr}
\hline Peak-load & Coef. & Robust Std. Err. & $\mathbf{t}$ & $\mathbf{P > t}$ & {$[\mathbf{9 5 \%}$ Conf. } & Interval] \\
\hline cons & -2223.98 & 643.629 & -3.46 & 0.001 & -3502.656 & -945.2934 \\
30 day card & -0.35936 & .1603029 & -2.24 & 0.027 & -.6778328 & -.0408935 \\
Employed & 0.834468 & .1817781 & 4.59 & 0.000 & .4733338 & 1.195602 \\
Petrol price & 5.865795 & 5.628623 & 1.04 & 0.300 & -5.316447 & 17.04804 \\
Supply of Subway & 0.230534 & 2.802021 & 0.08 & 0.935 & -5.336169 & 5.797237 \\
Income & -3.20066 & 1.264835 & -2.53 & 0.013 & -5.71348 & -.6878483 \\
Population & 1.526682 & .4123975 & 3.70 & 0.000 & .7073824 & 2.345982 \\
dfeb & -32.6744 & 71.46611 & -0.46 & 0.649 & -174.6543 & 109.3055 \\
dmars & -117.783 & 91.53026 & -1.29 & 0.201 & -299.6242 & 64.05751 \\
dapril & -181.558 & 81.82077 & -2.22 & 0.029 & -344.109 & -19.00653 \\
dmay & -173.466 & 74.40649 & -2.33 & 0.022 & -321.2869 & -25.64399 \\
djune & -250.352 & 82.7384 & -3.03 & 0.003 & -414.7259 & -85.97739 \\
djuly & -401.541 & 81.26365 & -4.94 & 0.000 & -562.985 & -240.0962 \\
daug & -311.995 & 73.27586 & -4.26 & 0.000 & -457.5705 & -166.4199 \\
dsep & -268.254 & 98.7188 & -2.72 & 0.008 & -464.376 & -72.13172 \\
doct & -117.854 & 130.9435 & -0.90 & 0.371 & -377.9958 & 142.2885 \\
dnov & -110.565 & 101.2959 & -1.09 & 0.278 & -311.8071 & 90.6768 \\
ddec & -84.2771 & -0.59 & 0.553 & -217.5565 & 117.3058 \\
dfeb30 & -50.1253 & .1489341 & 0.69 & 0.490 & -.1925964 & .3991707 \\
dmars30 & 0.103287 & .1862826 & 1.15 & 0.252 & -.1554927 & .5846732 \\
dapril30 & 0.21459 & .1665154 & 1.87 & 0.064 & -.0189514 & .6426722 \\
dmay30 & 0.31186 & .1568821 & 1.61 & 0.112 & -.0596339 & .5637134 \\
djune30 & 0.25204 & .1716226 & 1.14 & 0.255 & -.1444622 & .5374544 \\
djuly30 & 0.196496 & .1662964 & 0.17 & 0.864 & -.3017325 & .3590212 \\
daug30 & 0.028644 & .1516692 & 1.15 & 0.252 & -.1264298 & .4762049 \\
dsep30 & 0.174888 & .1845898 & 2.45 & 0.016 & .084705 & .8181446 \\
doct30 & 0.451425 & .2363618 & 1.21 & 0.229 & -.1831791 & .7559687 \\
dnov30 & 0.286395 & .1624946 & 0.97 & 0.333 & -.16475 & .4808977 \\
ddec30 & 0.336758 & & & & & \\
\hline & 0.158074 & & & &
\end{tabular}




\section{Appendix B2 - Final estimated regression peak-period}

Number of obs

R-squared $=0.9613$

Durbin-Watson 1.751

\begin{tabular}{lrrrrrr}
\hline Peak-load & Coef. & Robust Std. Err. & $\mathrm{t}$ & $\mathrm{P}>\mathrm{t}$ & {$[95 \%$ Conf. } & Interval] \\
\hline _cons & -2334.321 & 461.029 & -5.06 & 0.000 & -3248.558 & -1420.083 \\
30 day card & -.1936892 & .1023001 & -1.89 & 0.061 & -.3965542 & .0091758 \\
Employed & .8712096 & .1381674 & 6.31 & 0.000 & .5972185 & 1.145201 \\
Income & -2.896768 & 1.09877 & -2.64 & 0.010 & -5.07567 & -.7178659 \\
Population & 1.520843 & .3638614 & 4.18 & 0.000 & .7992927 & 2.242394 \\
dmay & -30.61346 & 8.65108 & -3.54 & 0.001 & -47.76887 & -13.45804 \\
djune & -136.7509 & 9.614649 & -14.22 & 0.000 & -155.8171 & -117.6847 \\
djuly & -378.8883 & 9.262057 & -40.91 & 0.000 & -397.2553 & -360.5213 \\
daug & -210.0258 & 7.919968 & -26.52 & 0.000 & -225.7314 & -194.3202 \\
dsep & -178.9292 & 71.84528 & -2.49 & 0.014 & -321.4011 & -36.45734 \\
dfeb30 & .0519181 & .0143809 & 3.61 & 0.000 & .0234003 & .0804359 \\
dsep30 & .2986212 & .1198347 & 2.49 & 0.014 & .0609845 & .5362578 \\
doct30 & .0812127 & .0216707 & 3.75 & 0.000 & .0382389 & .1241864 \\
dnov30 & .1413753 & .0229065 & 6.17 & 0.000 & .0959508 & .1867998 \\
ddec30 & .0675143 & .0157617 & 4.28 & 0.000 & .0362581 & .0987704 \\
\hline
\end{tabular}




\section{Appendix C1 - First regression off-peak period}

Number of obs

119

R-squared $=0.9506$

\begin{tabular}{lrrrrrr}
\hline Off-peak & Coef. & Robust Std. Err. & $\mathbf{t}$ & $\mathbf{P}>\mathbf{t}$ & {$[\mathbf{9 5 \%}$ Conf. } & Interval] \\
\hline -cons & -1905.661 & 607.6364 & -3.14 & 0.002 & -3112.837 & -698.4856 \\
30 day card & -.4090624 & .155505 & -2.63 & 0.010 & -.7180002 & -.1001246 \\
Employed & .7423903 & .1890795 & 3.93 & 0.000 & .3667509 & 1.11803 \\
Petrol price & 1.615296 & 5.29472 & 0.31 & 0.761 & -8.903589 & 12.13418 \\
Supply of Subway & 3.068288 & 2.728494 & 1.12 & 0.264 & -2.352343 & 8.488918 \\
Income & -2.159819 & 1.168195 & -1.85 & 0.068 & -4.480642 & .1610053 \\
Population & 1.134096 & .3831256 & 2.96 & 0.004 & .3729505 & 1.895242 \\
dfeb & -16.74607 & 71.22587 & -0.24 & 0.815 & -158.2487 & 124.7566 \\
dmars & -77.58795 & 84.29942 & -0.92 & 0.360 & -245.0635 & 89.88756 \\
dapril & -182.44 & 77.36333 & -2.36 & 0.021 & -336.1357 & -28.7442 \\
dmay & -140.561 & 75.86491 & -1.85 & 0.067 & -291.2799 & 10.15789 \\
djune & -217.7622 & 74.82076 & -2.91 & 0.005 & -366.4067 & -69.11773 \\
djuly & -351.9699 & 69.65506 & -5.05 & 0.000 & -490.3518 & -213.588 \\
daug & -326.5024 & 71.43283 & -4.57 & 0.000 & -468.4162 & -184.5886 \\
dsep & -225.619 & 88.30398 & -2.56 & 0.012 & -401.0503 & -50.18777 \\
doct & -150.4232 & 111.731 & -1.35 & 0.182 & -372.3962 & 71.54991 \\
dnov & -140.6187 & 87.70977 & -1.60 & 0.112 & -314.8694 & 33.63211 \\
ddec & -41.16764 & -0.07 & 0.947 & -146.145 & 136.6289 \\
dfeb30 & .145011 & 0.74 & 0.464 & -.181391 & .3947885 \\
dmars30 & .1066988 & .1736617 & 0.99 & 0.323 & -.1723121 & .5177064 \\
dapril30 & .1726971 & .1571586 & 2.40 & 0.018 & .0655287 & .6899748 \\
dmay30 & .3777518 & .1573917 & 1.80 & 0.075 & -.0295337 & .5958384 \\
djune30 & .2831523 & .1552116 & 1.88 & 0.064 & -.0171644 & .5995454 \\
djuly30 & .2911905 & .1421148 & 1.13 & 0.263 & -.1221739 & .4424978 \\
daug30 & .1464415 & 2.50 & 0.014 & .0750429 & .6569062 \\
dsep30 & .1601619 & .2040852 & 1.96 & 0.053 & -.0048469 & .8060547 \\
doct30 & .1804144 & 2.31 & 0.023 & .0588506 & .7756999 \\
dnov30 & .3659746 & .1411728 & 1.30 & 0.197 & -.097016 & .4639127 \\
ddec30 & .4089788 & & & & &
\end{tabular}




\section{Appendix C2 - Final estimated regression off-peak period}

Number of obs

R-squared

Durbin-Watson
119

$=0.9391$

1.692

\begin{tabular}{lrrrrrr}
\hline Off-peak & Coef. & Robust Std. Err. & $\mathbf{t}$ & $\mathbf{P}>\mathbf{t}$ & [95\% Conf. & Interval] \\
\hline _cons & -966.2101 & 208.4505 & -4.64 & 0.000 & -1379.529 & -552.8913 \\
30 day card & -.2656595 & .0776473 & -3.42 & 0.001 & -.4196197 & -.1116993 \\
Employed & .6583841 & .1338661 & 4.92 & 0.000 & .3929524 & .9238158 \\
Population & .523639 & .1665986 & 3.14 & 0.002 & .1933047 & .8539733 \\
djune & -72.58744 & 9.226143 & -7.87 & 0.000 & -90.88117 & -54.2937 \\
djuly & -278.2564 & 7.709683 & -36.09 & 0.000 & -293.5433 & -262.9696 \\
daug & -228.8903 & 45.62397 & -5.02 & 0.000 & -319.3542 & -138.4264 \\
dsep & -130.5703 & 67.63747 & -1.93 & 0.056 & -264.6829 & 3.542268 \\
dfeb30 & .0487524 & .015432 & 3.16 & 0.002 & .0181536 & .0793513 \\
daug30 & .1607483 & .0847602 & 1.90 & 0.061 & -.0073156 & .3288122 \\
dsep30 & .2075865 & .1146132 & 1.81 & 0.073 & -.0196703 & .4348434 \\
doct30 & .0999375 & .0178069 & 5.61 & 0.000 & .0646297 & .1352453 \\
dnov30 & .1328723 & .0231417 & 5.74 & 0.000 & .0869865 & .1787581 \\
ddec30 & .1395808 & .0158145 & 8.83 & 0.000 & .1082236 & .170938 \\
\hline
\end{tabular}




\section{Appendix D1 - Adjusted regression peak-period}

Number of obs

R-squared $=0.9547$

Durbin-Watson 1.675

\begin{tabular}{lrrrrrrr}
\hline Peak-load & Coef. & Robust Std. Err. & $\mathbf{t}$ & $\mathbf{P > t}$ & {$[\mathbf{9 5 \%}$ Conf. } & Interval] & VIF \\
\hline -cons & -450.2033 & 104.4433 & -4.31 & 0.000 & -657.2722 & -243.1343 & - \\
30 day card & -.1578765 & .0602299 & -2.62 & 0.010 & -.2772882 & -.0384649 & 4.5 \\
Employed & 1.025062 & .1339872 & 7.65 & 0.000 & .7594196 & 1.290705 & 2.85 \\
Petrol price & 12.31833 & 4.648592 & 2.65 & 0.009 & 3.102041 & 21.53461 & 6.12 \\
dfeb & 31.94502 & 8.719669 & 3.66 & 0.000 & 14.65743 & 49.23261 & 1.23 \\
dmay & -36.02891 & 8.9478 & -4.03 & 0.000 & -53.76879 & -18.28902 & 1.25 \\
djune & -143.8496 & 9.345504 & -15.39 & 0.000 & -162.378 & -125.3212 & 1.27 \\
djuly & -385.6994 & 10.89593 & -35.40 & 0.000 & -407.3016 & -364.0971 & 1.27 \\
daug & -217.2636 & 9.454239 & -22.98 & 0.000 & -236.0075 & -198.5197 & 1.28 \\
dsep & -23.74274 & 17.19877 & -1.38 & 0.070 & -57.84096 & 10.35549 & 1.27 \\
ddec & 39.49424 & 8.323433 & 4.74 & 0.000 & 22.99223 & 55.99626 & 1.26 \\
doct30 & .0700243 & .0218934 & 3.20 & 0.002 & .0266186 & .1134301 & 1.26 \\
dnov30 & .1359621 & .0230527 & 5.90 & 0.000 & .0902578 & .1816663 & 1.26 \\
\hline
\end{tabular}

\section{Appendix D2 - Adjusted regression off-peak period}

$$
\begin{array}{lr}
\text { Number of obs } & 119 \\
\text { R-squared } & 0.9376 \\
\text { Durbin-Watson } & 1.681
\end{array}
$$

\begin{tabular}{lrrrrrrr}
\hline Off-peak & Coef. & Robust Std. Err. & $\mathbf{t}$ & $\mathbf{P}>\mathbf{t}$ & [95\% Conf. & Interval] & VIF \\
\hline cons & -654.8751 & 268.2256 & -2.44 & 0.016 & -1186.658 & -123.0917 & \\
30 day card & -.1331852 & .0593622 & -2.24 & 0.027 & -.2508764 & -.0154939 & 5.39 \\
Employed & .8936241 & .146709 & 6.09 & 0.000 & .6027594 & 1.184489 & 3.52 \\
Petrol price & 8.47357 & 4.516382 & 1.88 & 0.063 & -.4805963 & 17.42774 & 6.47 \\
Supply & 3.311197 & 2.435795 & 1.36 & 0.017 & -1.518003 & 8.140397 & 2.07 \\
dfeb & 33.27307 & 8.092477 & 4.11 & 0.000 & 17.22894 & 49.31719 & 1.16 \\
djune & -77.52714 & 8.645411 & -8.97 & 0.000 & -94.6675 & -60.38677 & 1.18 \\
djuly & -282.3735 & 8.561207 & -32.98 & 0.000 & -299.3469 & -265.4001 & 1.18 \\
daug & -145.7114 & 9.489765 & -15.35 & 0.000 & -164.5257 & -126.897 & 1.19 \\
dsep & -21.15714 & 14.61751 & -1.45 & 0.015 & -50.13778 & 7.823499 & 1.18 \\
ddec & 81.85205 & 7.138621 & 11.47 & 0.000 & 67.69904 & 96.00506 & 1.19 \\
doct30 & .093671 & .0175963 & 5.32 & 0.000 & .0587846 & .1285573 & 1.17 \\
dnov30 & .1309415 & .0227971 & 5.74 & 0.000 & .085744 & .1761391 & 1.18 \\
\hline
\end{tabular}

